\title{
A histological and immunohistochemical study on the possible protective role of silymarin on cerebellar cortex neurotoxicity of lactating albino rats and their pups induced by gibberellic acid Original Article during late pregnancy and early postnatal period
}

\author{
Heba Kamal Mohamed and Hala Zein-El-Abedin Mohamed
}

Department of Human Anatomy and Embryology, Faculty of Medicine, Assiut University, Assiut, Egypt

\begin{abstract}
Introduction: Plant growth regulators (PGRs), especially gibberellic acid (GA3), are used to increase the production and the availability of the plants all the year. Silymarin has recently been reported to be a neuroprotective agent against much neurologic diseases.

Aim: To investigate the effects of GA3 treatment during late pregnancy and early postnatal periods on the rat's cerebellar cortex of lactating mothers and their pups. Besides, to detect the possible protective-role of silymarin.

Materials and Methods: Thirty (30) pregnant rats were randomly divided equally into three groups; control group (received distilled water orally daily from 14th day of the pregnancy until day 14 after delivery), GA3-treated group (received GA3 orally daily in a dose of $55 \mathrm{mg} / \mathrm{Kg}$ body weight from 14th day of the pregnancy until day 14 after delivery) and GA3/ silymarin-treated group (received GA3 orally daily in a dose of $55 \mathrm{mg} / \mathrm{Kg}$ body weight for the same periodconcomitantly with silymarin at a dose of $100 \mathrm{mg} / \mathrm{kg}$ body weight). At the end of experimental period, lactating mothers and their pups (two weeks old) were anesthetized, sacrificed, their cerebella were processed for histological and immunohistochemical evaluation. Morphometric studies and statistical analyses were conducted.

Results: GA3 induced cerebellar cortex histological and immunohistochemical insults in the form of disturbed architecture, degenerative changes, vacuolization, blood vascular dilatation and strong positive GFAP immunoreactive cells with longer and thicker processes. These insults were markedly ameliorated in GA3/silymarin-treated rats.

Conclusion: Administration of silymarin might protect against GA3 induced cerebellar neurotoxicity.
\end{abstract}

Received: 25 Feb 2018, Accepted: 19 Jun 2018

Key Words: Cerebellum, gibberellic acids, silymarin.

Corresponding Author: Heba K. Mohamed, Department of Human Anatomy and Embryology, Faculty of Medicine, Assiut University, Assiut, Egypt, Tel.: +201001016547, E-mail: hebaelgamae73@yahoo.com.

ISSN: $1110-0559$, Vol. 41 , No. 3

\section{INTRODUCTION}

Nowadays, many chemicals are used in different agriculture fields, of which the plant growth regulators (PGRs) where first reported in the $1930 \mathrm{~s}^{[1]}$. PGRs are also known as plant hormones ${ }^{[2]}$. Gibberellic acid (GA3) is a member of PGRs that are used in many countries ${ }^{[3]}$. GA3 is considered as one of the most active hormones of gibberellins. It affects many mechanisms of the plant growth including stem elongation by stimulating cell division, flowering and fruit development ${ }^{[4]}$. GA3 was used extensively to increase the growth of many fruits (strawberries and grapes) and vegetables (tomatoes, cabbages and cauliflower) $)^{[5]}$.

People might be exposed to residues of GA3 in diet that was derived from consumption of different fruits and vegetables treated with GA3. In addition occupational exposure of the agricultural workers to GA3 also occurs through inhalation of powder and dermal contact with that compound at work ${ }^{[6]}$. In animals, some studies demonstrated that chronic GA3 consumption increased the incidences of tumor formation and changed the hormones levels in serum, liver and kidneys ${ }^{[3]}$. GA3 could induce oxidative stress that leads to the generation of free radicals. It also causes cells damage in numerous organs; the heart, kidney, stomach, spleen and the liver of adult rats ${ }^{[7]}$. However, little information is available regarding the neurotoxic effect of this compound ${ }^{[8]}$.

Silymarin is found in the seeds of silybium marianum. It is standardized as a mixture of antioxidant flavonolignans ${ }^{[9]}$. Silymarin consists of four flavonolignanisomers; silybin, isosilybin, silydianin and silychristin. Among them, silybin is the most active and the commonly used. Silymarin is absorbed orally and is excreted mainly through bile as 
sulphates and conjugates ${ }^{[10]}$. Since its discovery in 1960 , silymarin has been recorded as the gold standard drug to treat liver disorders associated with alcohol consumption and viral hepatitis. Its hepato-protective effect is mainly due to tissue regenerative effects and its antioxidant properties $^{[10]}$. Silymarin has recently been reported as a neuroprotector against many disorders; Alzheimer's and Parkinson's diseases due to its ability to inhibit oxidative stress in the brain. It also displays additional advantages by influencing pathways such as $\beta$-amyloid aggregation, cellular apoptotic machinery and estrogenic receptor mediation $^{[11]}$.

GA3 heavy-use makes it an interesting subject to investigate its harmful effects on the histological structure of the cerebellum. Furthermore, the use of silymarin as a neuroprotective agent against GA3 neurotoxicity needs to be investigated. Therefore, this study aimed to study the influence of maternal administration of GA3 during late pregnancy and early postnatal periods on the histological structure of the cerebellum of the lactating mothers and their offsprings and to assess any possible protection by concomitant supplementation with silymarin.

\section{MATERIALS AND METHODS}

\section{Chemicals}

All the chemicals that were used in this work were of high commercially grade. GA3 $(2,4 \mathrm{a}, 7$-Trihydroxy1-methyl-8methylenegibb-3-ene-1, 10-dicarboxylic acid 1,4a-lactone) used was in the form of white crystalline powder and was purchased from Sigma -Aldrich chemical Co., Germany. Silymarin powder was purchased from sigma-Aldrich, USA. Glial Fibrillary Acid Protein (GFAP) was purchased from Thermo scientific Co.

\section{Experimental Animals}

A total number of 30 adult female and 15 male albino rats (180-200) gm were used in this work. These animals were housed in the animal house of Assiut University in cages of fine wood bedding that was changed three times a week. They were kept under light dark cycle (12/12) hours and at a $(25 \pm 5){ }^{\circ} \mathrm{C}$. All the rats were given food and water ad libitium. Separation between the adult male and female rats was done for 3 weeks to assure that the female rats were not pregnant. After this, female rats were allowed to mate in the ratio of 2 females to one male. Vaginal smears were taken by a glass rod that was inserted smoothly into the vagina; then the smears were spread on a slide and stained by Shori stain. The estrus period was characterized by the presence of non nucleated epithelial cells. After appearance of the mucous plug, the vaginal smear of pregnant rats was found to contain non nucleated epithelial cells, a large amount of mucous and leukocytes ${ }^{[12]}$. These experimental techniques were carried out in accordance with the international guidelines for the care and use of laboratory animals ${ }^{[13]}$.

\section{Experimental protocol}

The pregnant female rats were randomly divided into three groups (ten rats each):

Group I (Controls): the animals of this group were given distilled water orally daily via gastric tube from the 14th day of pregnancy until day 14 after delivery.

Group II (GA3-treated group): rats received GA3 oral daily dose of $55 \mathrm{mg} / \mathrm{Kg}$ body weight ${ }^{[14]}$ from the 14th day of pregnancy until day 14 after delivery by the way of a gastric tube.

Group III (GA3/silymarin-treated group): the animals of this group received GA3 oral daily dose of $55 \mathrm{mg} / \mathrm{Kg}$ body weight ${ }^{[14]}$ from the 14 th day of the pregnancy until day 14 after delivery by the way of gastric tube concomitantly with Silymarin. Silymarin powder was dissolved in sterile water and given orally by means of gastric tube at a dose of $100 \mathrm{mg} / \mathrm{kg}$ body weight ${ }^{[15]}$.

At the end of experimental period, dams (lactating mothers) and their female pups (two-weeks old) were sacrificed by an overdose of ether and perfused intracardially with saline and $4 \%$ paraformaldehyde solution.

\section{Histological study}

All animals were anaesthetized by ether inhalation. Their chest wall was opened. Animals were perfused trans-cardially through the left ventricle with $4 \%$ paraformaldehyde solution. The descending aorta was ligated before perfusion and the right atrium was opened once perfusion has started. The perfusion continued until the venous return from the right atrium was observed to be clear. The skull was opened and the cerebella were removed ${ }^{[16]}$.

\section{Light microscopic study}

For light microscopic study, the removed cerebella of animals in all groups were rapidly excised and cut conveniently into small pieces and were fixed in $10 \%$ formalin for two days. Then the tissues were dehydrated in ascending concentrations of alcohol, cleared in xylene and finally embedded in paraffin. Serial coronal sections about $5 \mu \mathrm{m}$ in thickness were prepared and stained by hematoxylin and eosin stain for demonstration of the histological structure ${ }^{[17]}$.

\section{Electron microscopic study}

For electron microscopic study, the cerebella of each group were dissected. Then, $1 \times 1 \mathrm{~mm}$ specimens were cut and fixed in $4 \%$ cold gluteraldehyde immediately after dissecting the animal for 24-48 hr. The specimens were then washed in phosphate buffer (PH7.2) 3-4times for 20 minutes each and post fixed in $1 \%$ OsO4 for $2 \mathrm{~h}$, after that washed in the same buffer 4 times. Dehydration by ascending grades of alcohol (30, 50, 70, 90 and 100\% for $2 \mathrm{~h}$ ) was done and embedding in epon araldite mixture. Semithin sections about $0.5 \mu \mathrm{m}$ in thickness were stained 
with Toluidine blue. Ultrathin sections of $50 \mathrm{~nm}$ in thickness were cut by an ultra-microtome from the chosen areas and were contrasted with uranyl acetate and lead citrate [18]. The ultrathin sections were photographed with transmission electron microscope (Joel- JEM- 100 CXII; Joel, Tokyo, Japan) in Assiut University Electron Microscopic Unit.

\section{Immunohistochemical study}

For the immunohistochemical study, the following procedures were considered; fixation in $10 \%$, neutral formalin for 48 hours, dehydration, clearing and finally embedding in paraffin. Paraffin sections were cut at $5 \mathrm{um}$ in thickness. Sections were stained with modified avidin -biotin peroxidase technique for Glial Fibrillary Acidic Protein (GFAP) for the demonstration of the astrocytes. The sections were deparaffinized and hydrated. To unmask the antigen, the sections were treated with $0.01 \mathrm{M}$ citrate buffer (PH 6.0) for about 10 minutes. Then, the sections were incubated in $0.3 \% \mathrm{H} 2 \mathrm{O} 2$ for half an hour to abolish the effect of endogenous peroxidase activity before blocking with $5 \%$ horse serum for $1-2 \mathrm{~h}$. The slides were first incubated with primary antibody (1:100 monoclonal mouse anti GFAP) at 4Co for $18-20 \mathrm{~h}$, then washed and incubated with biotinylated secondary antibodies and then with avidin-biotin complex. Finally, the sections were prepared with $0.05 \%$ diaminobenzidine slides and stained with hematoxylin, dehydratedand mounted. The GFAP positive cells were brown and their nuclei appeared blue ${ }^{[19]}$. Negative controls were processed according to the same protocol, except for the use of the primary antibody. A brain slide was used as the positive control for GFAP.

\section{Morphometric and Statistical studies}

The mean thickness of the external granular layer of two weeks old rats and the Purkinje cell layer of two weeks old and adult rats were measured using image analysis system ((Leica Qwin 500; Imaging Systems, Cambridge, UK)). This procedure was performed using the sections stained by hematoxylin and eosin in ten non-overlapping fields in ten randomly chosen sections belonging to five animals for each group (at magnification $\times 400$ ). The obtained data represented as mean values \pm standard deviation (SD) and analyzed using Mann-Whitney test to compare the means between the different groups, using the software statistical package of social science 'version 16' SPSS (Chicago, Illinois, USA). The level of significance $(p)$ value was $0.05^{[20]}$.

\section{RESULTS}

\section{Two-weeks old rats}

Histological results

\section{Light microscopic results}

Hematoxylin and Eosin (H\&E) stained paraffin sections revealed that the cerebellar cortex of two weeks old control animals was formed of the following layers; the external granular layer, outer molecular layer, middle Purkinje layer and inner granular layer. The external granular layer was formed of small rounded cells arranged in two or three rows. They had rounded deeply stained nuclei and scantly acidophilic cytoplasm. The molecular layer had many rounded and oblongata cells which were migrating in rows perpendicular to the pial surface. The Purkinje cells were arranged in a single row. They contained well defined rounded vesicular nuclei and prominent nucleoli. Their cytoplasm was pale acidophilic and contained basophilic granules. The inner granular layer was stuffed with welldefined clumps of rounded cells with rounded deeply stained nuclei and scanty acidophilic cytoplasm (Fig. 1A). Semithin sections showed that the Purkinje cells were ovoid cells with basophilic cytoplasm containing rounded vesicular nuclei with prominent nucleoli. Negative Golgi region was noticed in these cells. Bergmann astrocytes surrounded the Purkinje cells. They had pale nuclei and pale cytoplasm. The inner granular layer showed groups of rounded cells. These cells had rounded heterochromatic nuclei with prominent nucleoli and pale scanty cytoplasm (Fig. 2A).

In the GA3-treated group, H\&E-stained sections of the cerebellar cortex exhibited the presence of prominent spongiosis noticed as numerous vacuolated areas in the external granular, molecular, Purkinje and granular layers. Apparent reduction in the thickness of the external granular layer was observed. Its cells had shrunken cell bodies with hardily identified nuclei and deeply stained cytoplasm. The molecular layer showed some cells with deeply stained pyknotic nuclei. Disturbance in the linear organization of the Purkinje cells was observed. Purkinje cells seen were irregular, distorted and shrunken. They exhibited rarified nuclei and darkly stained cytoplasm. Some cells appeared to have hardly identified nuclei. The granule cells accumulated in the form of follicles. Most of the granule cells appeared small with ill-defined outline and hardly identified nuclei (Fig. 1B). In toluidine blue stained sections, GA3-treated group showed some shrunken Purkinje cell bodies with irregular outline, hardly identified nuclei and vacuolated cytoplasm were noticed in the inner granular layer. Some cells appeared to have deeply stained nuclei and cytoplasm. Bergmann astrocytes had pale nuclei with prominent nucleoli and well stained cytoplasm. The granule cells were widely separated from each other and most of them were irregular in shape. Some cells were apparently shrunken with ill-defined nuclei. Other cells have rarified nuclei. Many vacuolated areas observed within the outer molecular layer, the Purkinje layer and the inner granular layer (Fig. 2B).

H\&E stained sections of GA3/silymarin-treated group showed more or less normal appearance of the cortical layers. The Purkinje cells retained their normal linear organization. They contained rounded vesicular nuclei and prominent nucleoli. The granule cells appear nearly similar to the control. No observable differences from the control 
group were noticed in the external granular and molecular layers (Fig. 1C). The semi-thin sections of this group showed apparent improvement in the three cortical layers .The Purkinje cells appeared slightly irregular in shape and had rounded vesicular nuclei with prominent nucleoli. Negative Golgi region could be observed in the basophilic cytoplasm. Bergmann astrocytes surrounded the Purkinje cells. They had pale nuclei and pale cytoplasm. The granular layer showed nearly normal granular cells with vesicular nuclei containing coarse clumps of heterochromatin. Few granule cells had darkly stained nuclei. Some vacuolated areas were still observed within the outer molecular layer (Fig. 2C).

\section{Electron microscopic results}

Ultastructurally, the cerebellar cortex of two weeks old control group showed that the Purkinje cells appeared to have large oval euchromatic nuclei and well- defined nucleoli. Slight indentation of the nuclear envelope was present. The cytoplasm showed the presence of numerous mitochondria with intact membranes and regular cristae, Golgi apparatus, free ribosomes and numerous welldeveloped rough endoplasmic reticulum cisternae (Figs. 3A\&B). Bergmann astrocytes were noticed. They exhibited pale euchromatic nuclei and pale cytoplasm. Few cytoplasmic organelles as mitochondria, rough endoplasmic reticulum cisternae and few ribosomes were noticed. The cell revealed extended processes which contained few gliofilaments and mitochondria (Fig. 4A). The granule cells within the inner granular layer exhibited rounded or oval nuclei with clumps of heterochromatin. They had little cytoplasm with few mitochondria, strands of rough endoplasmic reticulum, lysosome and ribosomes (Fig. 5A)

Ultrastructure examination of GA3-treated group confirmed the light microscopic findings. The Purkinje cells had oval euchromatic nucleus with prominent nucleolus. Faint nuclear envelope (nuclear ghost) was detected (Fig. 3C). Dilated cisternae of rough endoplasmic reticulum, marked vacuolation, lysosomes and apparent decrease in the amount of free ribosomes were noticed in the cytoplasm. Some mitochondria were damaged with disrupted cristae and others were vacuolated (Figs. 3C and D). The Bergmann astrocytes were seen ensheathing Purkinje cells with their processes. They had irregular outline and electron-dense nuclei. No organelles could be identified in the darkly stained cytoplasm (Fig. 4B). The granular cells revealed features of apoptosis in the form of marked condensation of the nuclear chromatin into clumps and irregularity of the nuclear membrane. Some cells showed rarified cytoplasm that contained few organelles. Apparent decrease in the amount of free ribosomes and damaged mitochondria were seen. In addition, marked cellular and intercellular vacuolations were noticeable (Fig. 5B).

Ultrathin sections of GA3/silymarin-treated group revealed that there was normal appearance of Purkinje cells with euchromatic nuclei, prominent nucleoli and a slightly electron-dense cytoplasm. Some cells showed faint nuclear envelope. Apparently healthy mitochondria, free ribosomes, few vacuoles and short strands of rough endoplasmic reticulum were present in the cytoplasm (Fig. 3E). The Bergmann astrocytes showed euchromatic nucleus and displayed blocks of condensed chromatin distributed on the inner side of the nuclear envelope. The cytoplasm of these cells had free ribosomes and mitochondria (Fig. 4C). The granule cells within the internal granular layer showed the presence of rounded or oval nuclei with clumps of heterochromatin. The cytoplasm contained free ribosomes, strands of rough endoplasmic reticulum and mitochondria. Intercellular vacuolations were still noticed. Oligodendrocytes with chromatin condensation were detected between the granular cells (Fig. 5C).

\section{Immunohistochemical results}

For demonstration of glial fibrillary acidic protein (GFAP) positive cells, immunohistochemical staining showed that the cerebellar cortex of two weeks old control group had few scattered GFAP immunoreactive cells with long and thin processes in the different cortical layers (Fig. 6A). GA3-treated group revealed more abundant GFAP positive cells which appeared larger with relatively longer and thicker processes in the three cortical layers as compared with the control (Fig. 6B). GA3/silymarintreated group showed Positive expression of GFAP which was more or less similar to that noticed in the control rats (Fig. 6C).

\section{Morphometric results}

A significant reduction in the thickness of the external granular layer of GA3-treated group (group II) as compared to control group (group I) was detected. No significant change was observed in GA3/silymarin-treated group (group III) versus group I (Table land Histogram 1). The thickness of the Purkinje layer was significantly increased in group II as compared with group I. No significant change was observed in group III versus group I (Table 2 and Histogram 2).

\section{Adult rats (lactating mothers)}

\section{Histological results}

\section{Light microscopic results}

Examination of H\&E stained sections of the cerebellar cortex of adult control animals showed more differentiation of the lamination pattern as compared to the previous age and the following layers could be distinguished; the outer molecular layer, the middle Purkinje layer and the inner granular layer. The outer molecular layer contained few rounded and oblongata cells together with numerous fibers. The Purkinje layer was formed of a single row of large pyriform cells with large rounded vesicular nuclei, prominent nucleoli and slightly basophilic cytoplasm. The cells had thick and long apical dendrites. The next 
granular layer was formed of well-defined clumps of rounded cells with rounded dark nuclei and scanty pale acidophilic cytoplasm. Small clear lightly stained non cellular areas called cerebellar islands (glomeruli) were also seen in between the granular nerve cells (Fig.7A). Semithin sections showed that the cerebellar cortex had sparse population of neurons in the outer molecular layer. The Purkinje cells revealed deeply stained basophilic cytoplasm and open face nuclei with prominent nucleoli. Bergmann astrocytes surrounded the Purkinje cells; they had pale nuclei and pale cytoplasm. The granular cells appeared rounded with deeply stained nuclei and pale scanty cytoplasm. Some blood vessels were observed in the inner granular layer (Fig. 8A). The cells were more differentiated compared with the previous age.

After treatment with GA3, H\&E stained sections showed obvious degenerative changes that were observed specifically in the Purkinje cell layer and were reflected on the other two layers. The linear organization of the Purkinje cells was disturbed with marked disarrangement. Some cells were displaced downwards in the inner granular layer and upwards in the molecular layer. Others were fallen off leaving remarkable empty spaces. The Purkinje cells appeared shrunken and irregular in shape. They contained deeply stained cytoplasm and hardly identified nuclei. The molecular layer had rounded and oblongata cells. These cells were distorted and surrounded by halos of empty spaces. The granule cells showed shrunken cell bodies, deeply stained cytoplasm and hardly identified nuclei. Marked spongiosis were seen in the three cortical layers as vacuolated areas (Fig. 7B). Toluidine blue stained sections showed that the Purkinje cells appeared with disturbed linear organization. They appeared deformed and lost their characteristic pyriform shape. Faint vacuolated cytoplasm and hardly identified nuclei were detected in some cells. Other cells were degenerated leaving multiple vacuolated areas. The Bergmann astrocytes surrounding the Purkinje cells were darkly stained. Irregular outline of their nuclei and peripheral chromatin condensation were detected. Congested blood vessels were observed in the Purkinje layer. The granular cells appeared more deeply stained with darker nuclei as compared with the control group. Some neurons showed vacuolated cytoplasm and others showed pyknotic nuclei. Marked spongiosis were seen as vacuolated areas in the three cortical layers (Fig. 8B).

The cerebellar cortex of GA3/silymarin treated rats showed marked regression in the neurotoxic effect of GA3. H\&E stained sections revealed a histological pattern nearly similar to the control group. The cerebellar cortex exhibited well- arranged outer molecular layer, middle Purkinje layer and inner granular layer. Wide sparse population of neurons was present in the outer molecular layer; rounded and oblongata cells. Purkinje cells were arranged in a single row between the molecular and the granular layers. They retained their characteristic pyriform shape. They had large rounded vesicular nuclei, prominent nucleoli and slightly basophilic cytoplasm. The next granular layer contained compactly disposed rounded cells with rounded dark nuclei and scanty pale acidophilic cytoplasm. Cerebellar islands (glomeruli) were also seen in between the granular cells (Fig.7C). In toluidine blue stained sections of this group, the Purkinje cells had basophilic cytoplasm and pale vesicular nuclei with prominent nucleoli. However few distorted and darkly stained cells were detected in between the normal ones. Bergmann astrocytes surrounded the Purkinje cells. They had pale nuclei and pale cytoplasm. The granular cells had normal appearance with rounded deeply stained nuclei and pale scanty cytoplasm. Some congested blood vessels could be detected and some vacuolated areas were still noticed (Fig. 8C).

\section{Electron microscopic results}

Ultrastructural examination of the cerebellar cortex of adult control group showed that the Purkinje cells were identified by their position, large size, euchromatic nuclei and well- defined nucleoli. The nuclear envelope was characterized by shallow dimples in which strands of rough endoplasmic reticulum accumulated forming the nuclear cap region. The cytoplasm was rich with abundant amount of rough endoplasmic reticulum organized into aggregates of parallel cisternae, free ribosomes, well developed Golgi apparatus and mitochondria with intact membranes and regular cristae (Figs. 9A\&B). The Bergmann astrocytes were observed ensheathing the Purkinje cells. They had pale euchromatic nuclei. The cytoplasm was pale and had free ribosomes and few mitochondria. The astrocytic process contained few gliofilaments and mitochondria (Fig. 10A). The ultrastructure of the granule cells showed the presence of rounded or oval nuclei with clumps of heterochromatin. The cytoplasm contained free ribosomes, few strands of rough endoplasmic reticulum and few mitochondria. The granule cells were surrounded with myelinated nerve fibers. Oligodendrocytes with condensed chromatin were detected between the granular cells (Fig. 11A).

Prominent ultrastructural alterations were observed in GA3-treated group. Regarding the Purkinje cells, some cells had destructed and interrupted cell membrane (Fig. 9C). Nuclear changes were detected as marked in folding of the nuclear envelope (Fig. 9D). Atrophic changes were evident in some Purkinje neurons leaving empty spaces between them. In addition, cytoplasmic ultrastructural changes were detected as vacuolation, few short and dilated strands of rough endoplasmic reticulum, lysosomes and apparent decrease in the amount of ribosomes. Distorted mitochondria were observed. Some of them were swollen with rarified matrix and ill-defined cristae (Figs. 9C\&D). The Bergmann astrocytes were observed surrounding the Purkinje cells. They exhibited euchromatic nuclei and peripheral chromatin condensation. They seemed to be shrunken with mere shell of cytoplasm. Vacuoles and electron dense distorted mitochondria were observed in the cytoplasm (Fig. 10B). The granular layer had granule cells with rounded or oval nuclei. Some of them showed irregular nuclear envelope. Other cells showed peripheral 
chromatin condensation. Rarified cytoplasm contained distorted mitochondria with a heterogenous matrix was noticed. Marked cellular and intercellular vacuolations were present. Notice oligodendrocytes with condensed nuclear chromatin (Fig. 11B).

In GA3/silymarin-treated group, the Purkinje cells exhibited a similar ultrastructural appearance to that of the control; euchromatic nuclei with prominent nucleoli and well-defined nuclear envelope. The cytoplasm was slightly electron-dense and was rich with abundant amount of rough endoplasmic reticulum organized into aggregates of parallel cisternae, free ribosomes, and mitochondria with intact membranes and regular cristae. The mitochondria seemed like those of the control group (Fig. 9E). Both Bergmann astrocytes and granule cells displayed a very similar ultrastructure to that of the control. The Bergmann astrocytes showed oval nuclei. Free ribosomes and few mitochondria were present in the cytoplasm (Fig. 10C). The granular cells appeared more or less normal and showed the presence of round or oval nuclei with heterochromatin. The cytoplasm contained free ribosomes, few strands of rough endoplasmic reticulum and few mitochondria. Myelinated nerve fibers and Oligodendrocytes were observed between the granule cells (Fig. 11C).

\section{Immunohistochemical results}

Immunohistochemically, apparently large GFAP positive cells with relatively longer processes were noticed in the adult control group as compared with the previous age (Fig. 12A). GA3-treated group revealed more numerous and larger GFAP positive cells with thicker processes in comparison with the adult control group in the three cortical layers (Fig. 12B). In GA3/silymarin-treated group, Positive expression of GFAP was noticed in the three cortical layers which were nearly similar to that in the control group. GFAP expression in this group revealed marked reduction compared to that in GA3 treated adult rats (Fig. 12C).

\section{Morphometric results}

The thickness of the Purkinje layer increased significantly in GA3-treated group (group II) as compared to control group (group I). No significant change was observed in GA3/silymarin-treated group (group III) versus group I (Table 3 and Histogram 3).

Table 1: Mean value \pm SD of external granular layer thickness of two weeks old rats of different groups

\begin{tabular}{lccc}
\hline External granular layer & Group I & Group II & Group III \\
\hline Mean \pm SD & $27.44 \pm 1.84$ & $22.69 \pm 1.20$ & $29.03 \pm 1.96$ \\
Range & $24.6-30.9$ & $21.1-24.1$ & $26.7-31.9$ \\
$P$-value & & $0.001^{*}$ & 0.114 \\
\hline
\end{tabular}

Mann-Whitney Test

* Statistical significant difference $(P<0.05)$

Table 2: Mean value \pm SD of Purkinje layer thickness of two weeks old rats of different groups

\begin{tabular}{lccc}
\hline Purkinje layer & Group I & Group II & Group III \\
\hline Mean \pm SD & $36.25 \pm 2.09$ & $47.68 \pm 4.95$ & $34.18 \pm 3.00$ \\
Range & $34.1-39.1$ & $40.5-54.6$ & $26.3-35.0$ \\
$P$-value & & $0.004^{*}$ & 0.128 \\
\hline
\end{tabular}

Mann-Whitney Test

* Statistical significant difference $(P<0.05)$

Table 3: Mean value \pm SD of Purkinje layer thickness of adult rats (lactating mothers) of different groups

\begin{tabular}{lccc}
\hline Purkinje layer & Group I & Group II & Group III \\
\hline Mean \pm SD & $26.65 \pm 2.16$ & $40.93 \pm 5.14$ & $25.71 \pm 2.58$ \\
Range & $24.0-30.1$ & $30.9-45.6$ & $22.5-30.9$ \\
$P$-value & & $0.001^{*}$ & 0.372 \\
\hline
\end{tabular}




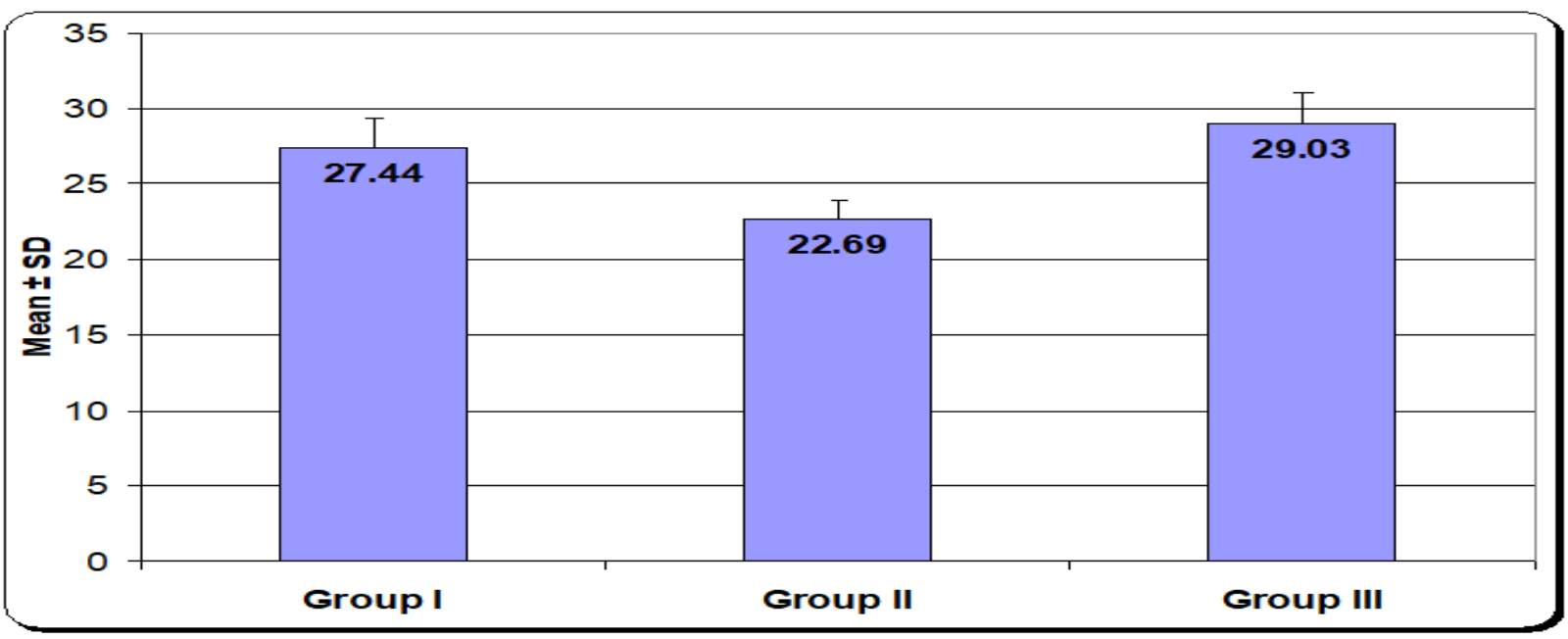

Histogram 1: Mean value \pm SD of external granular layer thickness of two weeks old rats of different groups

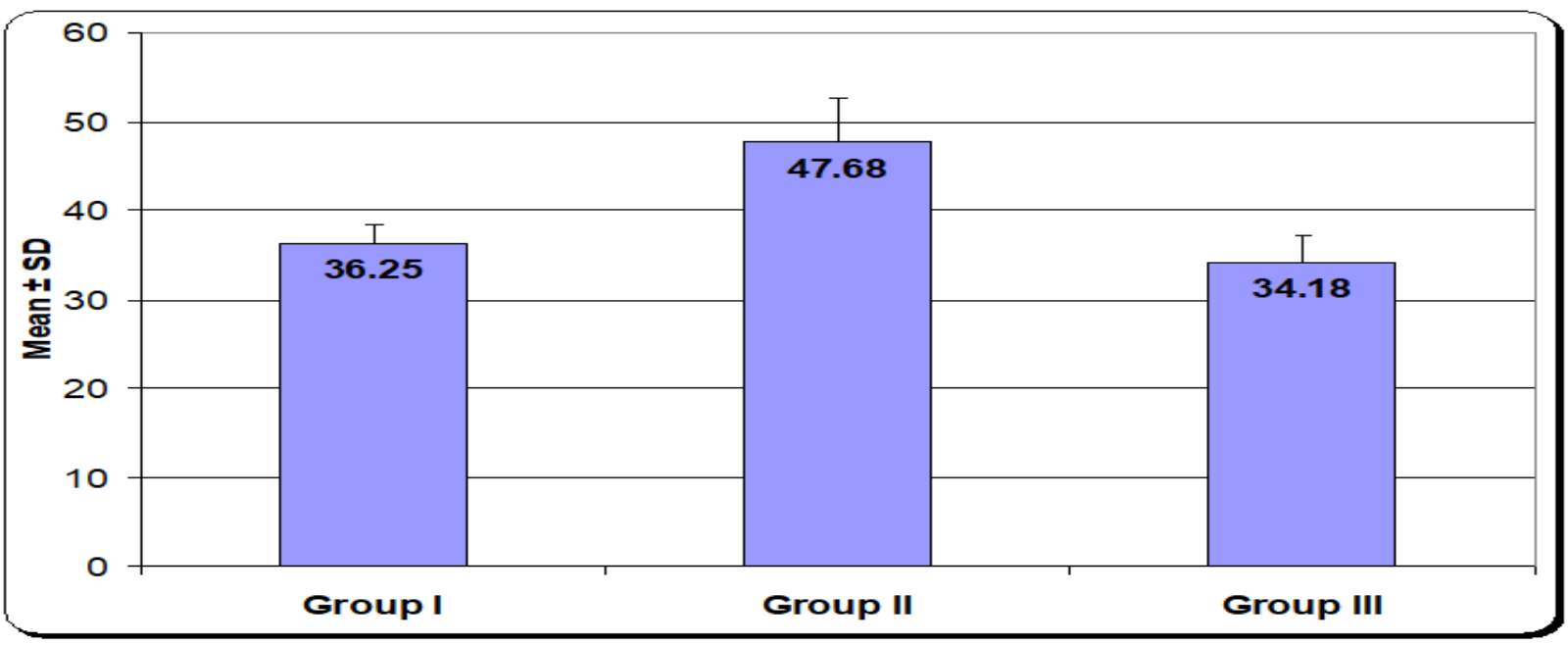

Histogram 2: Mean value \pm SD of Purkinje layer thickness of two weeks old rats of different groups

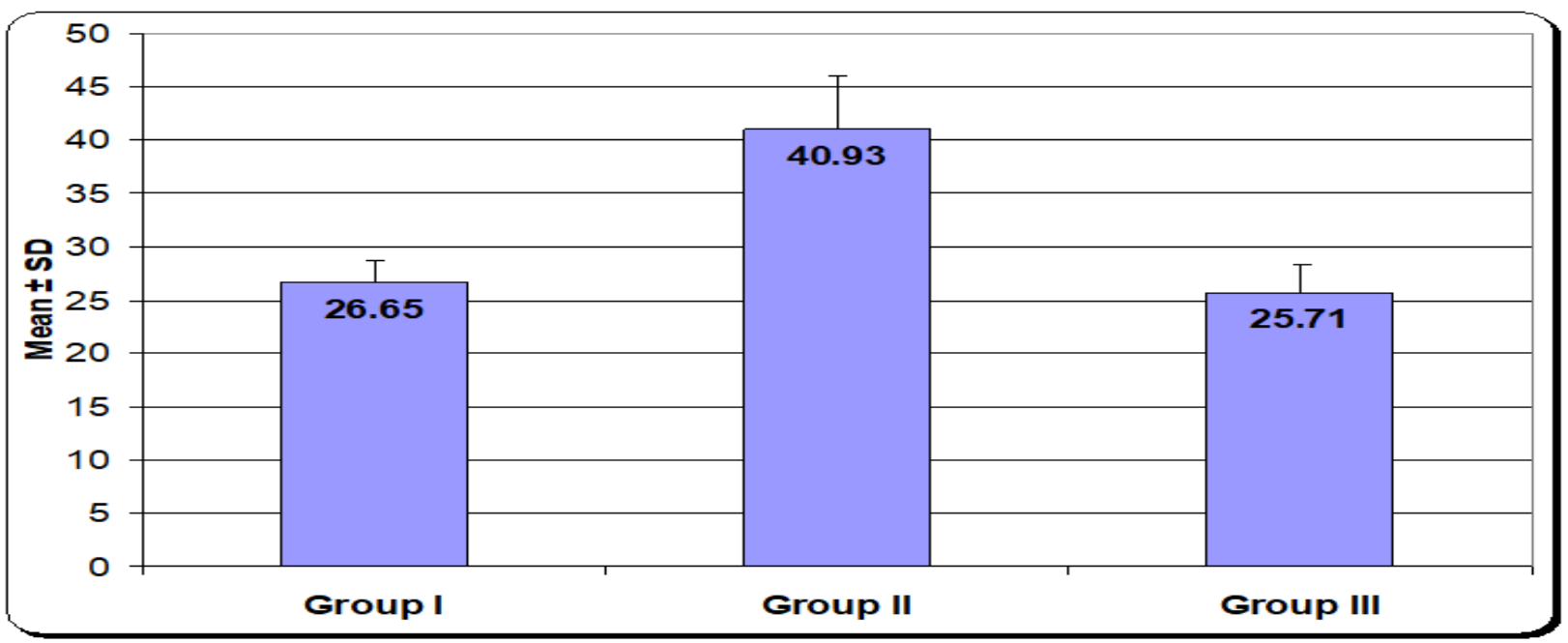

Histogram 3: Mean value \pm SD of Purkinje layer thickness of adult rats (lactating mothers) of different groups. 


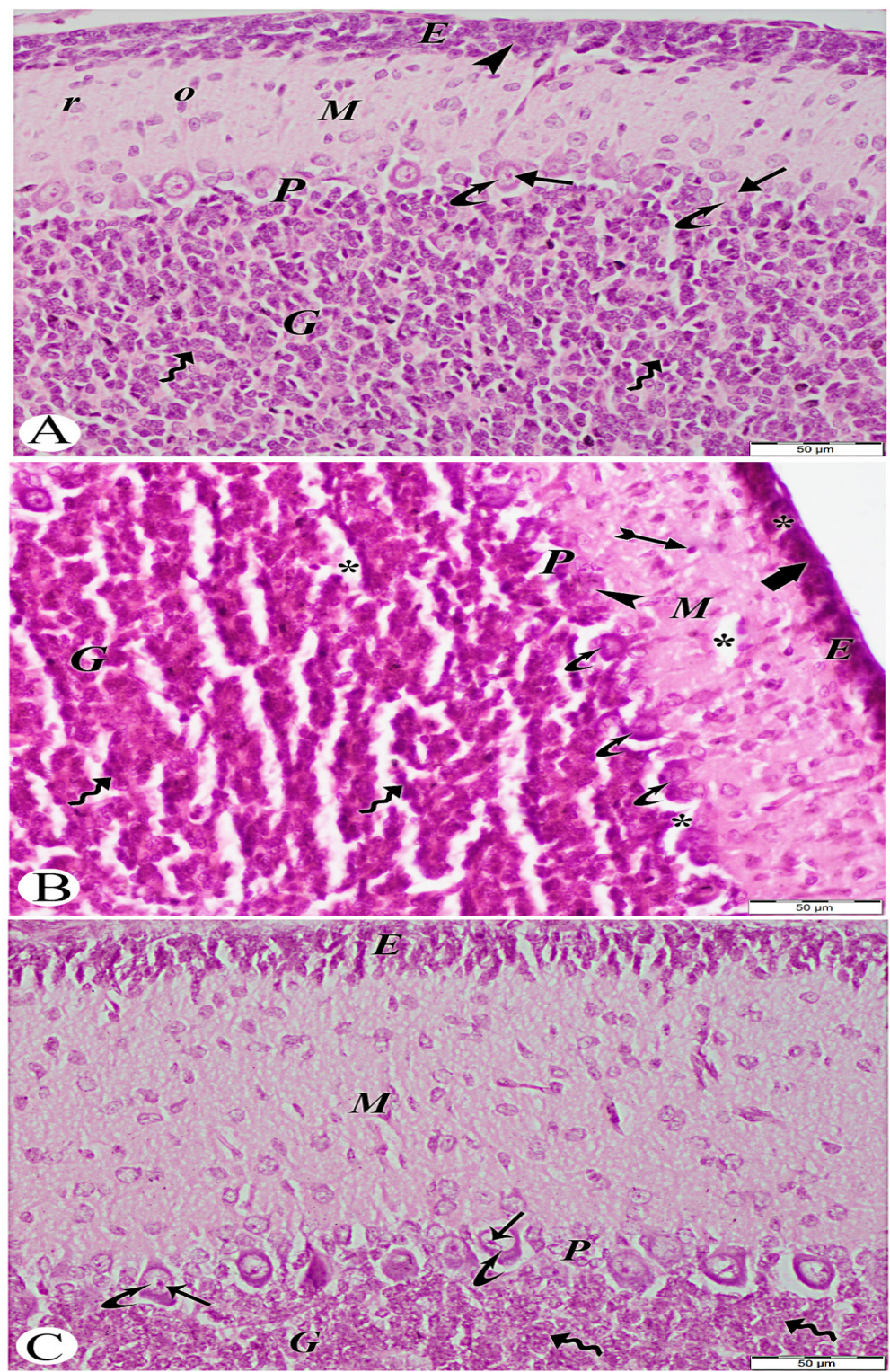

Fig. 1: Paraffin sections in 2 weeks old rats' cerebellar cortex stained by H\&E. (1A) Control group showing that the cerebellar cortex is formed of the external granular layer (E), outer molecular layer (M), middle Purkinje layer (P) and inner granular layer (G).The external granular layer is formed of small rounded cells arranged in two or three rows with rounded deeply stained nuclei and scantly acidophilic cytoplasm (arrow head). The molecular layer has many rounded (r) and oblongata (o) cells. Purkinje-cells arranged in a single row. They contain well defined rounded vesicular nuclei (curved arrows) and prominent nucleoli (arrows). Their cytoplasm is pale acidophilic and contains basophilic granules. The inner granular layer is stuffed with well-defined clumps of rounded cells with rounded deeply stained nuclei (wavy arrows) and scanty cytoplasm; (1B) GA3-treated group showing prominent spongiosis as numerous vacuolated areas (*) in the cortical layers with apparent reduction in the thickness of the external granular layer (E). Its cells have shrunken cell bodies with hardly identified nuclei and deeply stained cytoplasm (thick arrow). The molecular layer (M) shows some cells with deeply stained pyknotic nuclei (tailed arrow). Disturbance in the linear organization of the middle Purkinje layer (P) is observed. Purkinje cells seen are irregular, distorted and shrunken and exhibit rarified nuclei and darkly stained cytoplasm (curved arrows). Some cells appear to have hardly identified nuclei (arrowhead). The inner granule layer (G) shows cellular accumulation in the form of follicles and most of cells appear small with ill-defined outline and hardly identified nuclei (wavy arrows); (1C) GA3/silymarin-treated group showing more or less normal appearance. The Purkinje cell layer $(\mathrm{P})$ retains normal linear organization .The cells contain rounded vesicular nuclei (curved arrows) and prominent nucleoli (arrows). The granule cells $(\mathrm{G})$ appear nearly similar to the control (wavy arrows). No observable difference from the control group is noticed in the external granular (E) and molecular (M) layers.

$\mathrm{H} \& \mathrm{E}, \mathrm{X} 400$. 

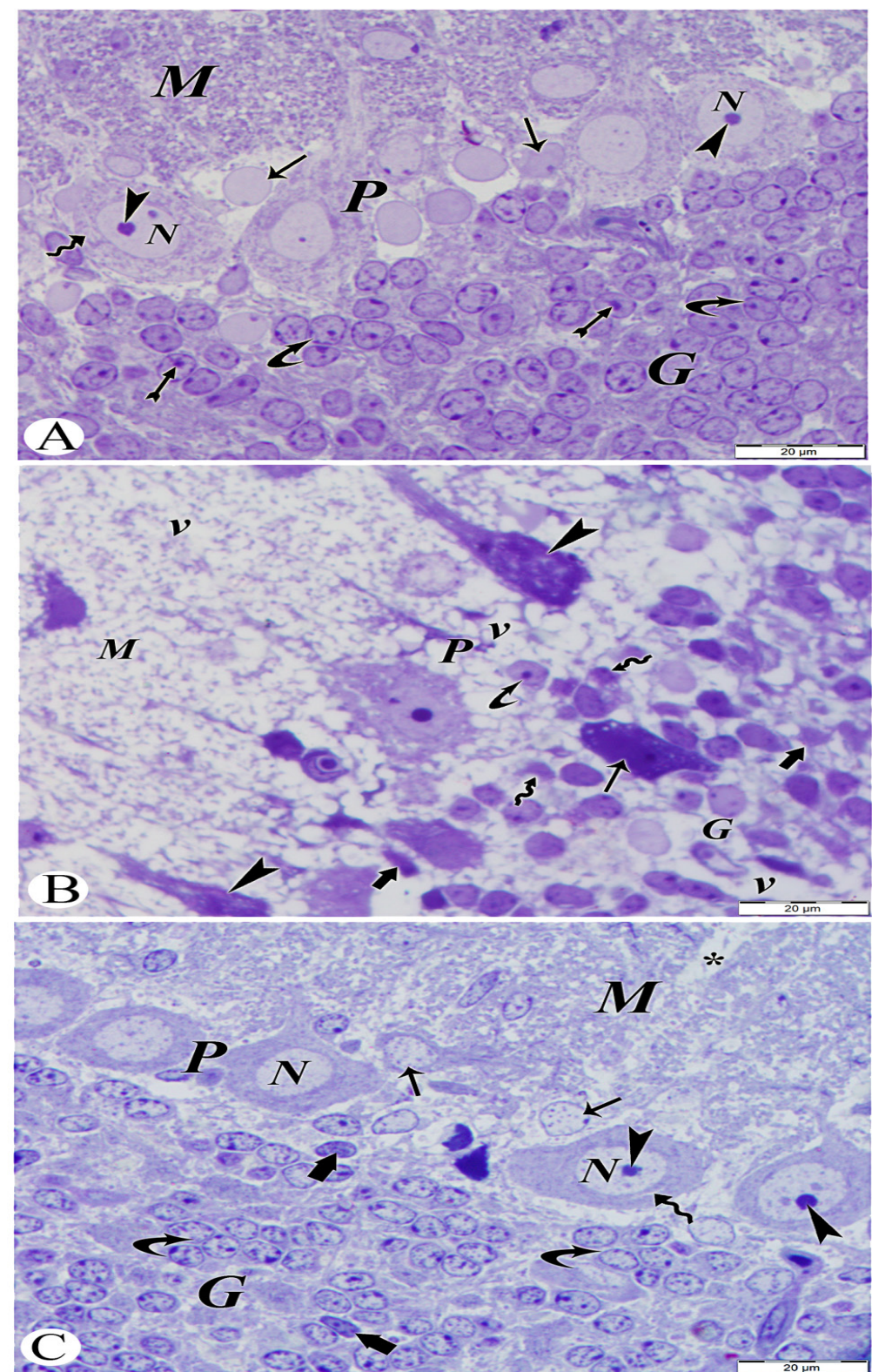

Fig. 2: Semithin sections in 2 weeks old rats' cerebellar cortex stained by Toluidine blue. (1A) Control group showing (M), (P) and (G) layers. The Purkinje cells are ovoid in shape with basophilic cytoplasm containing rounded vesicular nuclei $(\mathrm{N})$ with prominent nucleoli (arrow heads) and negative Golgi region (wavy arrow). Bergmann astrocytes are noticed surrounding the Purkinje cells; they have pale nuclei and pale cytoplasm (arrows). The inner granular layer has groups of rounded cells with rounded heterochromatic nuclei (curved arrows), prominent nucleoli (tailed arrows) and pale scanty cytoplasm; (1B) GA3-treated group rat showing many vacuolated areas (v) within (M), (P) and $(\mathrm{G})$ layers. Some shrunken Purkinje cell bodies with irregular outline, hardly identified nuclei and deeply stained vacuolated cytoplasm are noticed within the inner granular layer (arrow). Some cells appear to have deeply stained nuclei and cytoplasm (arrowheads). Bergmann astrocytes have pale nuclei with prominent nucleoli and well stained cytoplasm (curved arrow). Some granule cells are irregular darkly stained (thick arrows) or apparently shrunken with ill-defined nuclei (wavy arrows); (1C) GA3/silymarin-treated group showing (M), (P) and $(\mathrm{G})$ layers. The Purkinje cells appear slightly irregular in shape and have rounded vesicular nuclei $(\mathrm{N})$ with prominent nucleoli (arrowheads). Negative Golgi region can be observed in the basophilic cytoplasm (wavy arrow). Bergmann astrocytes surrounding the Purkinje cells are noticed. They have pale nuclei and pale cytoplasm (arrows). The granular layer shows nearly normal granule cells with vesicular nuclei containing coarse clumps of heterochromatin (curved arrows). Few granule cells have darkly stained nuclei (thick arrows). Some vacuolated areas $(*)$ are still observed within the outer molecular layer.

Toluidine blue, X1000. 

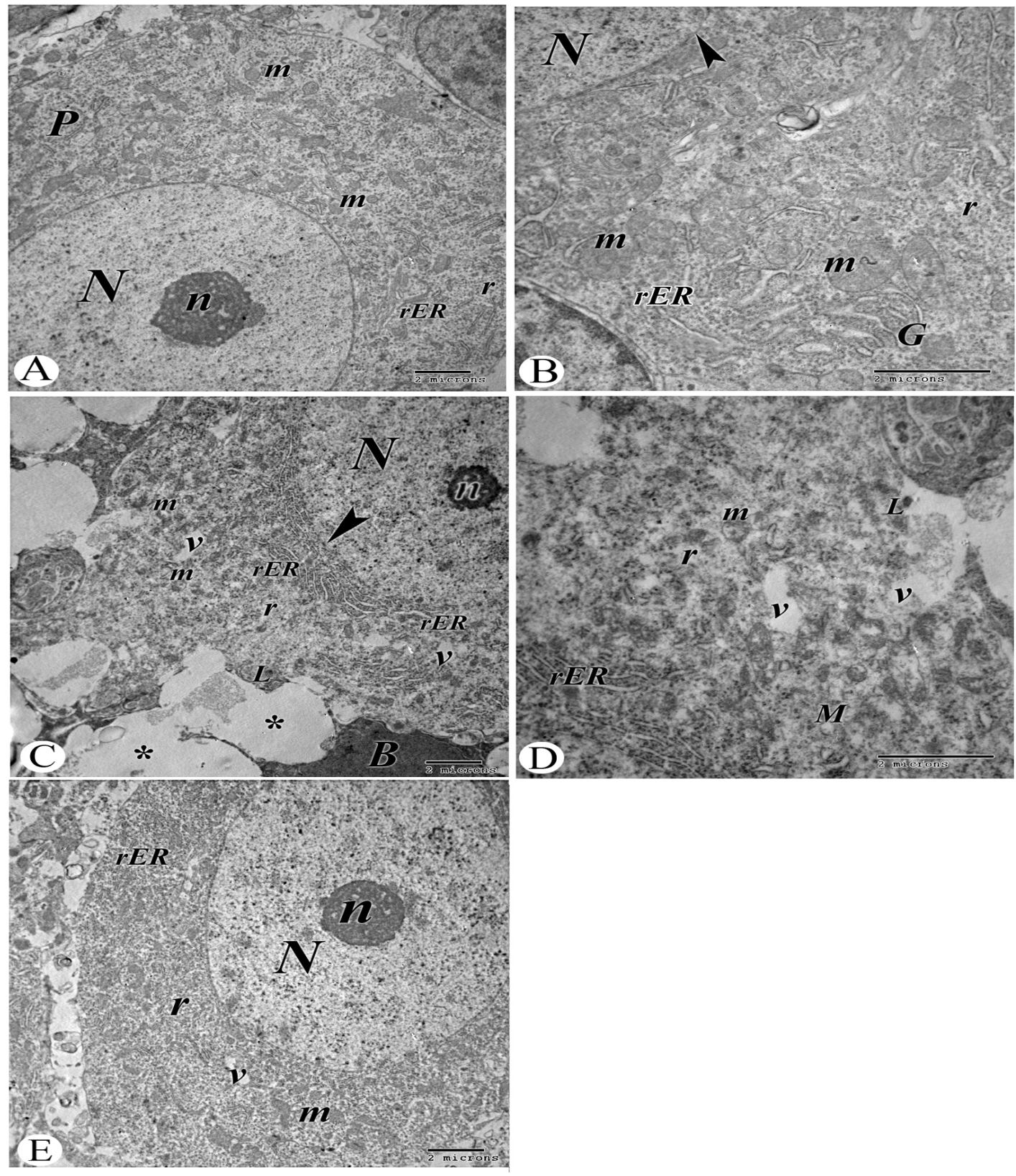

\section{(1)}

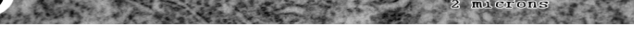

Fig. 3: TEM of the Purkinje cells of 2 weeks old rats' cerebellar cortex. (1A, 1B) Control group showing Purkinje cells (P). A large oval euchromatic nucleus $(\mathrm{N})$ with slight indentation of the nuclear envelope (arrow head) and well- defined nucleolus (n) can be noticed. The cytoplasm shows the presence of numerous mitochondria $(\mathrm{m})$ with intact membranes and regular cristae, free ribosomes (r), Golgi apparatus (G) and numerous well-developed rough endoplasmic reticulum cisternae (rER). TEM, X4800, X10000, respectively; (1C, 1D) GA3-treated group showing Purkinje cells. An oval euchromatic nucleus (N) and a less prominent nucleolus (n) are seen. Faint nuclear envelope (nuclear ghost) can be observed (arrow head). The cytoplasm reveals dilated cisternae of (rER), vacuolations (v), apparent decrease in the amount of free ribosomes (r) and lysosomes (L). Note that some mitochondria are damaged with disrupted cristae (m) and others are vacuolated (M). Empty spaces surrounding the cell $(*)$ are found. Part of adjacent Bergmann (B) astrocyte with electron-dense nucleus and darkly stained cytoplasm is noticed. TEM, X4800, X10,000 respectively; (1E) GA3/silymarin-treated group showing nearly normal ultrastructure of the Purkinje cell with euchromatic nucleus (N), prominent nucleolus (n) and a slightly electron-dense cytoplasm. Apparently healthy mitochondria (m), ribosomes (r) and short strands of (rER) are present in the cytoplasm. Few vacuoles (v) can be noticed. 


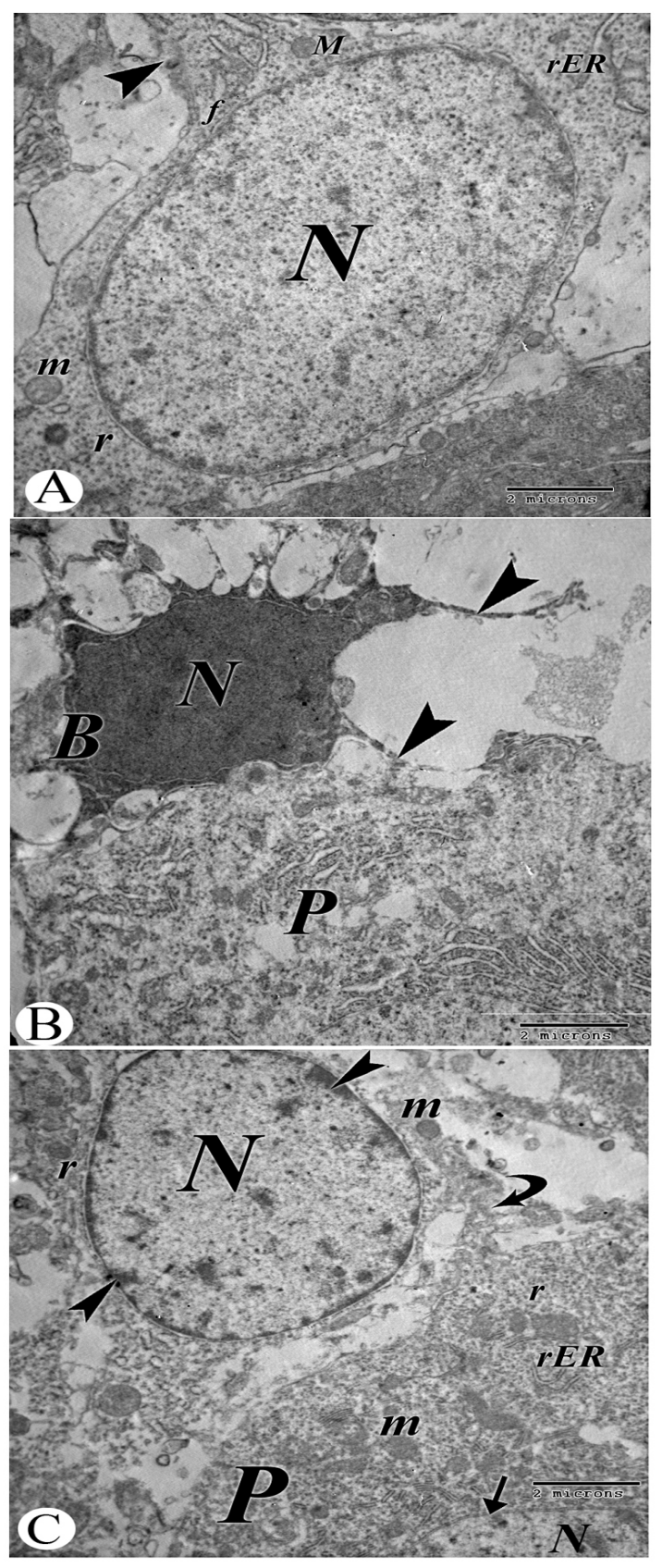

Fig. 4: TEM of the Bergmann astrocytes of 2 weeks old rats' cerebellar cortex. (1A) Control group showing a Bergmann astrocyte with its pale euchromatic nucleus $(\mathrm{N})$. Few cytoplasmic organelles such as mitochondria $(\mathrm{m}),(\mathrm{rER})$ and few ribosomes $(\mathrm{r})$ are detected in the pale cytoplasm. Notice its extended processes (arrow head) which contains few gliofilaments (f) and mitochondria (M); (1B) GA3-treated group showing a Bergmann astrocyte (B) with irregular outline ensheathing the Purkinje cell (P) with its processes (arrow heads). It has an electron-dense nucleus $(\mathrm{N})$ and darkly stained cytoplasm with hardly identified organelles in the dark cytoplasm; (1C) GA3/silymarintreated group showing a Bergmann astrocyte with euchromatic nucleus $(\mathrm{N})$. Blocks of condensed chromatin distributed on the inner side of the nuclear envelope (arrowheads). The cytoplasm displays free ribosomes (r) and mitochondria (m). Part of the adjacent Purkinje cell (P) is noticed ensheathed with the processes of the Bergmann astrocyte (curved arrow). The Purkinje cell has euchromatic nucleus $(\mathrm{N})$ and a slightly electron-dense cytoplasm. Faint nuclear envelope (arrow) is observed. Notice the presence of apparently healthy mitochondria (m), ribosomes(r) and short strands of (rER) in the cytoplasm.

TEM, X7200. 


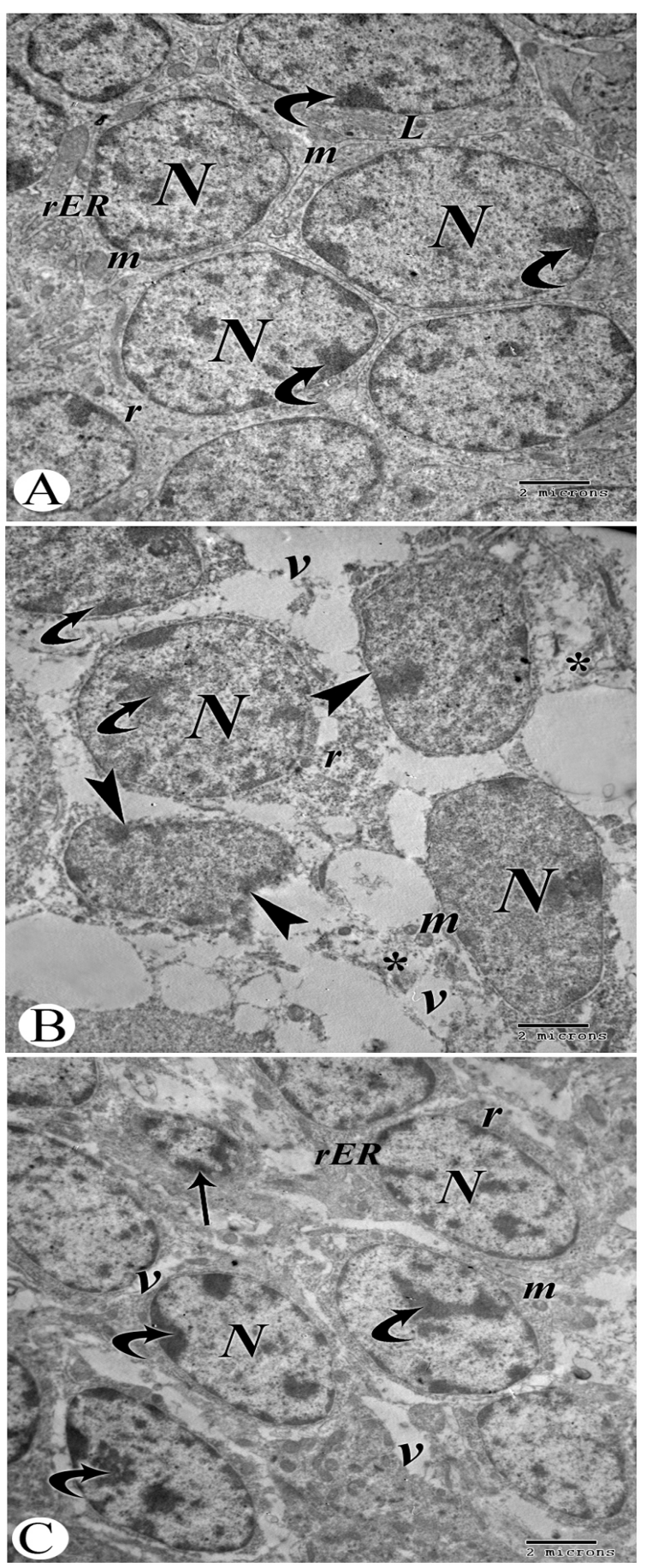

Fig. 5: TEM of the granule cells of 2 weeks old rats' cerebellar cortex. (1A) Control group showing granule cells with rounded or oval nuclei (N) with clumps of heterochromatin (curved arrows). Notice the presence of a thin rim of cytoplasm containing few mitochondria (m), strands of (rER), lysosomes (L) and ribosomes (r); (1B) GA3-treated group showing that the cells have rounded or oval more electron dense nuclei (N) with marked condensation of the nuclear chromatin into clumps (curved arrows) and irregularity of the nuclear membrane (arrow heads). Some cells show rarified cytoplasm (*) that contains few organelles. Apparent decrease in the amount of ribosomes (r), damaged mitochondria (m) and marked cellular and intercellular vacuolations (v) are noticeable. (1C) GA3/silymarin-treated group showing that the cells are more or less normal with rounded or oval nuclei $(\mathrm{N})$ having clumps of heterochromatin (curved arrows). The cytoplasm contains ribosomes (r), $(\mathrm{rER})$ and mitochondria $(\mathrm{m})$. Intercellular vacuolations (v) are still noticed. Oligodendrocyte (arrow) with chromatin condensation is detected between the granule cells.

TEM, X4800 


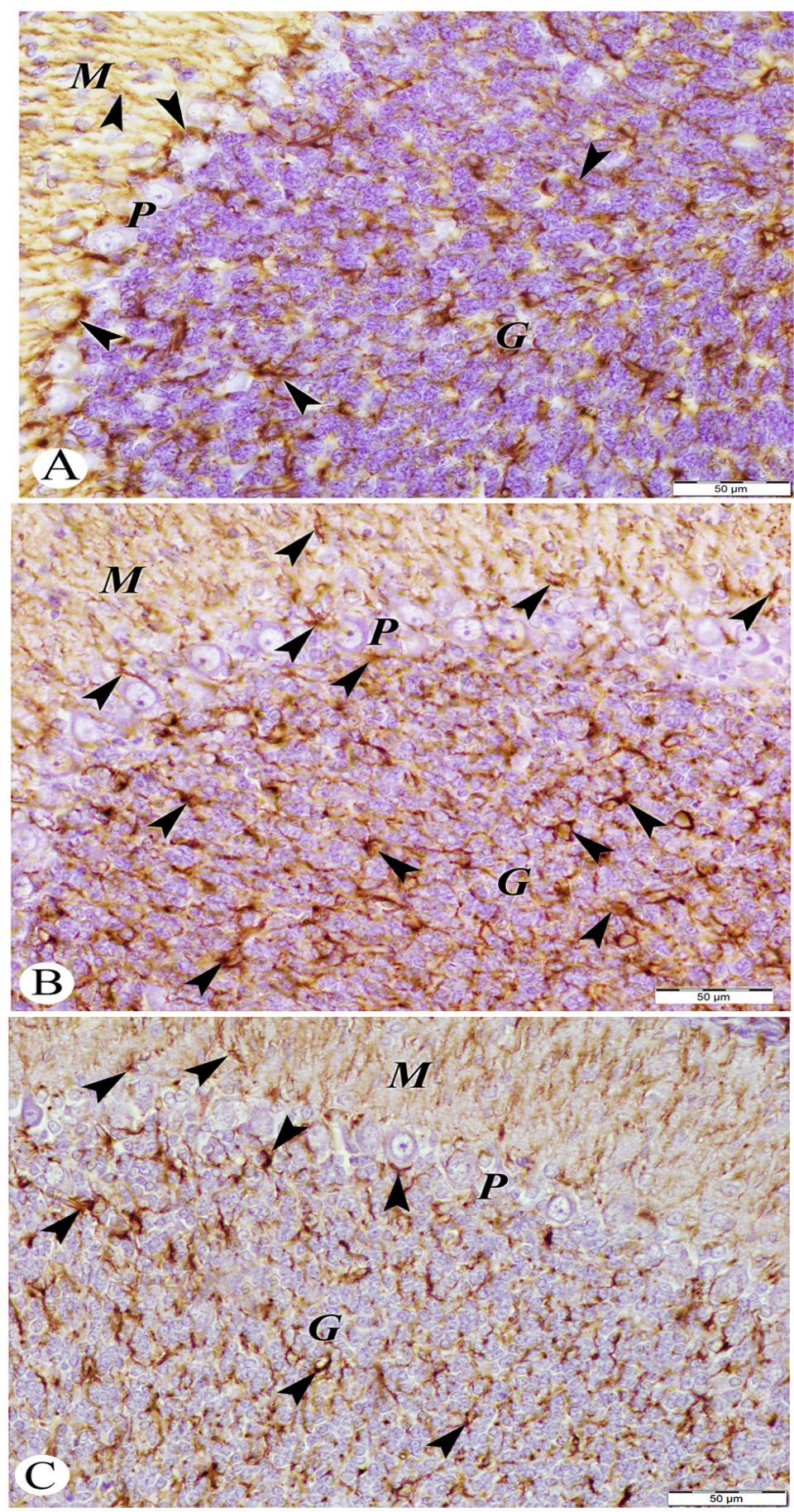

Fig. 6: Glial fibrillary acidic protein (GFAP) immunohistochemically stained sections in 2 weeks old rats' cerebellar cortex. (1A) Control group showing scattered GFAP immunoreactive cells with long and thin processes (arrow heads) in the different cortical layers (M), (P) and (G); (1B) GA3-treated group showing more abundant GFAP positive cells in the different cortical layers which appear larger with relatively longer and thicker processes (arrow heads) as compared with the control ; (1C) GA3/silymarin-treated group showing positive expression of GFAP which is more or less similar to that noticed in the control rats (arrow heads).

GFAP immunostain, X400. 


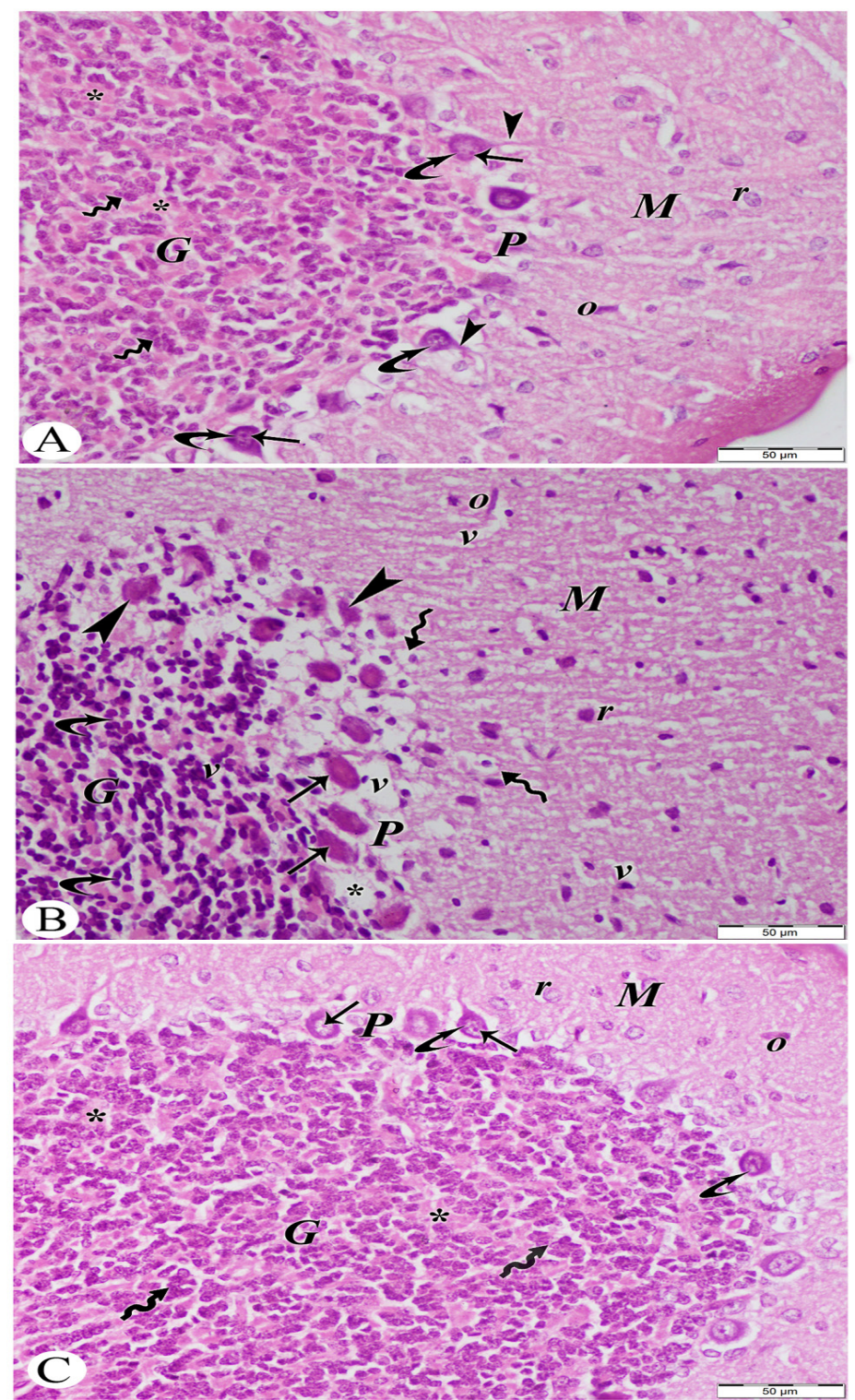

Fig. 7: Paraffin sections in the adult rats' (lactating mothers') cerebellar cortex stained by H\&E. (1A) Control group showing more differentiation of the lamination pattern as compared with the previous age and the following layers can be distinguished; molecular (M), Purkinje $(\mathrm{P})$ and granular $(\mathrm{G})$. The molecular layer contains few rounded (r) and oblongata cells (o) together with numerous fibers. The Purkinje layer is formed of a single row of large pyriform cells with large rounded vesicular nuclei (curved arrows), prominent nucleoli (arrows). The cells have thick and long apical dendrites (arrow heads). The next granular layer is formed of well-defined clumps of rounded cells with rounded dark nuclei (wavy arrows) and scanty pale acidophilic cytoplasm. Small clear lightly stained non cellular areas called cerebellar islands (glomeruli) are also seen $\left(^{*}\right)$ in between the granular nerve cells ; (1B) GA3-treated group showing obvious degenerative changes specially in $(\mathrm{P})$ layer that are reflected on the other two layers; $(\mathrm{M})$ and $(\mathrm{G})$ layers. The linear organization of the Purkinje cells is disturbed with marked disarrangement. Some cells are displaced downwards in the inner granular layer and upwards in the molecular layer (arrow heads). Others are fallen off leaving remarkable empty spaces $(*)$. The Purkinje cells appear shrunken and irregular in shape. They contain deeply stained cytoplasm and hardly identified nuclei (arrows). The molecular layer has rounded (r) and oblongata cells (o). These cells are distorted and surrounded by halos of empty spaces (wavy arrows). The granule cells show shrunken cell bodies, deeply stained cytoplasm and hardly identified nuclei (curved arrows). Marked spongiosis are seen in the three cortical layers as vacuolated areas (v); (1C) GA3/silymarin-treated group showing the successive three layers of the cerebellar cortex; (M), (P) and (G) layers. Wide sparse population of neurons are present in the outer molecular layer; rounded (r) and oblongata cells (o). Purkinje cells are arranged in a single row between the molecular and the granular layers. They retain their characteristic pyriform shape. They have large rounded vesicular nuclei (curved arrows), prominent nucleoli (arrows) and slightly basophilic cytoplasm. The granular layer contains compactly disposed rounded cells with rounded dark nuclei (wavy arrows) and scanty pale acidophilic cytoplasm. Cerebellar islands (glomeruli) are also seen in between the granule cells $(*)$.

H\&E, X400. 


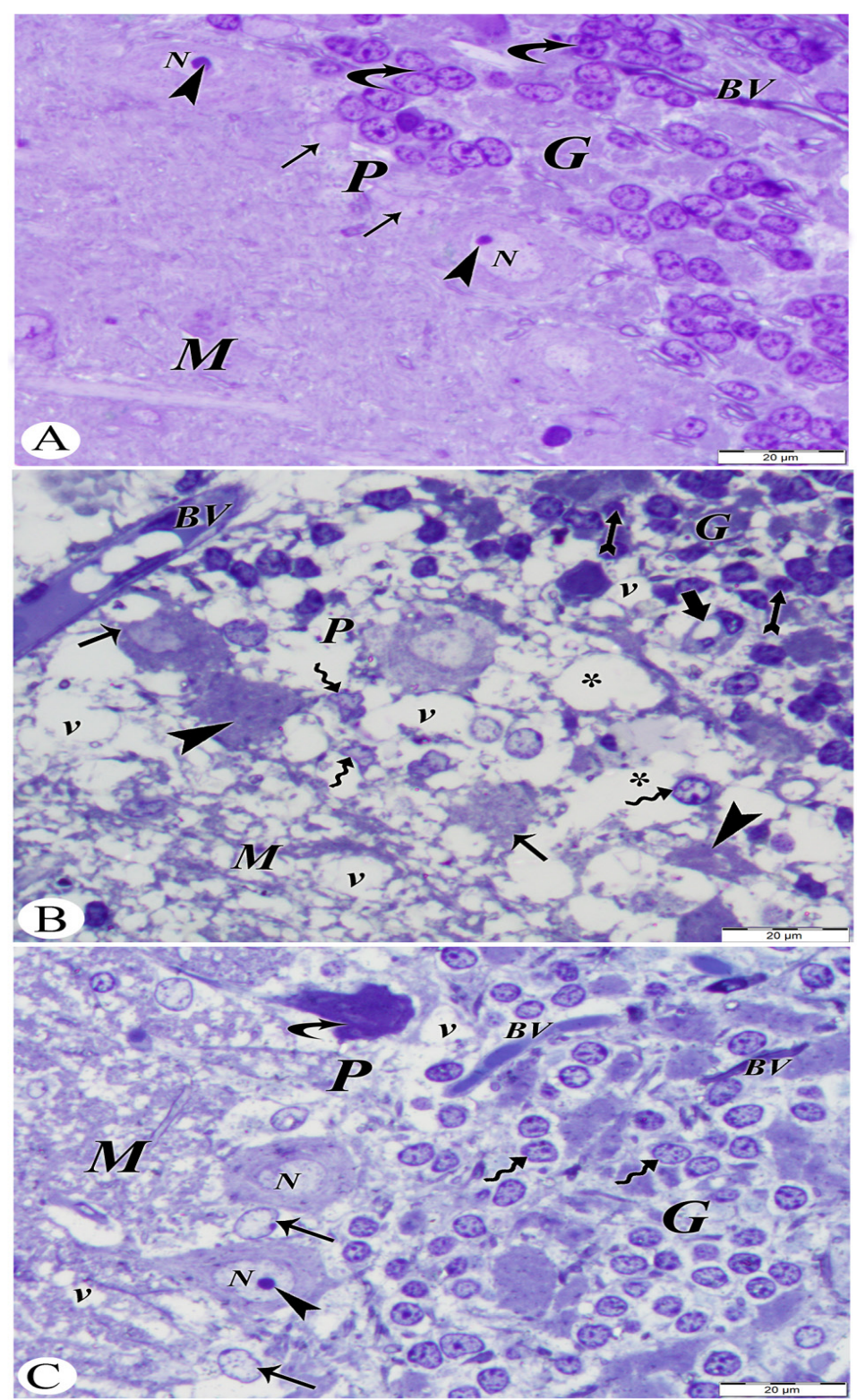

Fig. 8: Semithin sections in the adult rats' cerebellar cortex stained by toluidine blue. (1A) Control group showing the cerebellar cortex arranged in three successive strata; (M), (P) and (G). Sparse population of neurons is noticed in the outer molecular layer. The Purkinje cells show open face nuclei $(\mathrm{N})$ with prominent nucleoli (arrow heads). Note Bergmann astrocytes (arrows) surrounding the Purkinje cells; they have pale nuclei and pale cytoplasm. The granular cells appear rounded with deeply stained nuclei (curved arrows) and pale scanty cytoplasm. Blood vessels (BV) can be noticed in the inner granular layer. The cells are more differentiated compared with the previous age; (1B) GA3-treated group showing (M), (P) and (G) layers. The Purkinje cells show disturbed linear organization. They appear deformed and lose their characteristic pyriform shape. Deeply stained vacuolated cytoplasm (arrows) and hardly identified nuclei (arrow heads) are detected in some cells. Other cells are degenerated leaving multiple vacuolated areas $\left(^{*}\right)$. The Bergmann astrocytes surrounding the Purkinje cells appear darkly stained with irregular outline of the nuclei and peripheral chromatin condensation (wavy arrows). Congested dilated blood vessels (BV) are detected in the Purkinje cell layer. The granular cells appear more deeply stained with darker nuclei as compared with the control. Some neurons show vacuolated cytoplasm (thick arrow) and others show pyknotic nuclei (tailed arrows). Marked spongiosis are seen in the three cortical layers as vacuolated areas (v); (1C) GA3/silymarin-treated group showing the cerebellar cortex which is arranged in three successive layers; (M), (P) and (G). Sparse population of neurons is noticed in the molecular layer. The Purkinje cells show basophilic cytoplasm and pale vesicular nuclei $(\mathrm{N})$ with prominent nucleoli (arrow head). However few distorted and darkly stained cells are detected in between the normal ones (curved arrow). Bergmann astrocytes (arrows) surrounding the Purkinje cells are noticed; they have pale nuclei and pale cytoplasm. The granular cells have normal appearance; rounded deeply stained nuclei and pale scanty cytoplasm (wavy arrows). Notice the presence of slightly congested blood vessels (BV). Some vacuolated areas are still noticed (v).

Toluidine blue, X1000. 

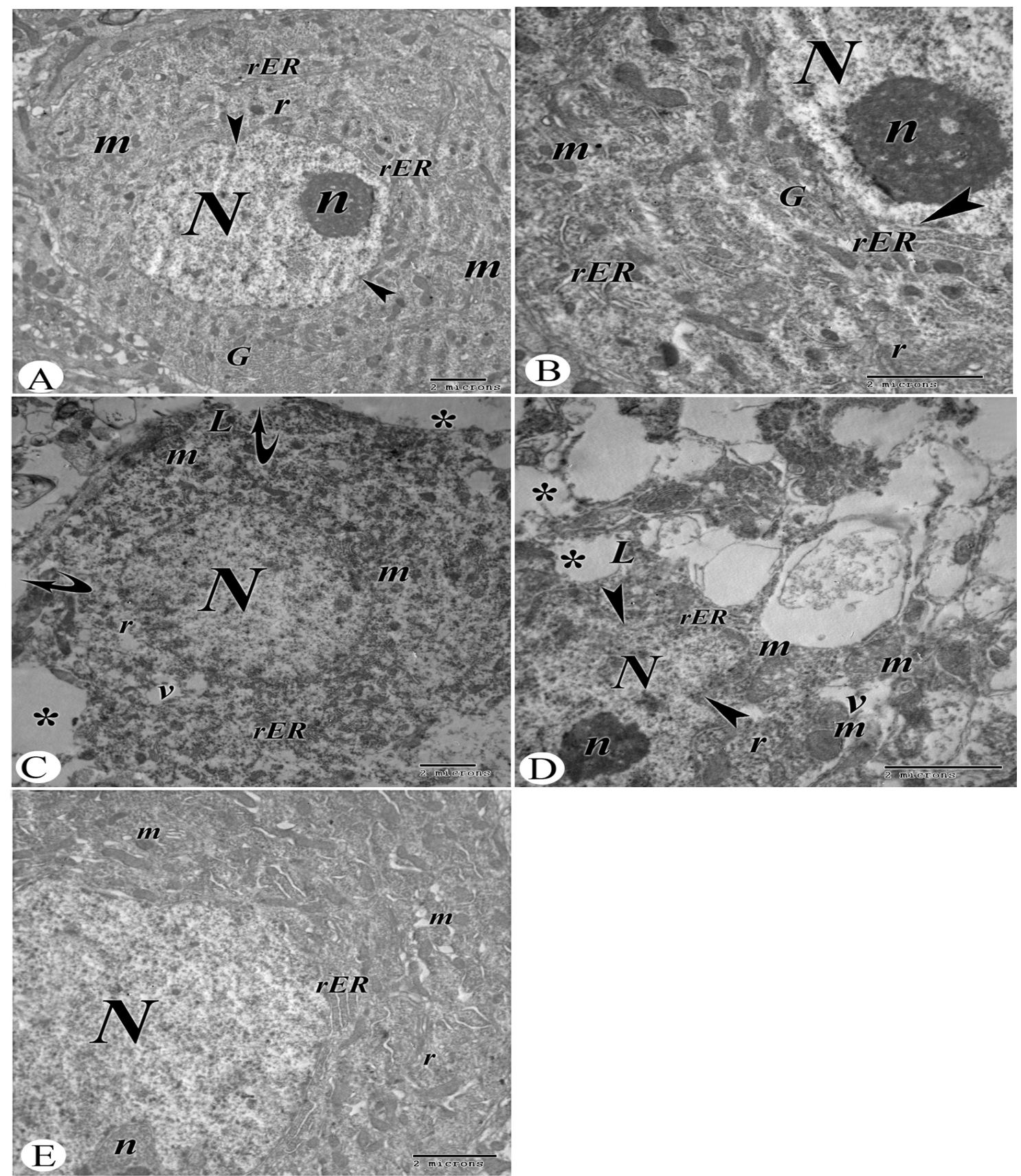

Fig. 9: TEM of the Purkinje cells of adult rats' cerebellar cortex. (1A, 1B) Control group showing euchromatic nucleus (N) and well-defined nucleolus (n). The nuclear envelope is characterized by shallow dimples (arrowheads) in which strands of (rER) accumulate forming the nuclear cap region. The cytoplasm is rich with abundant amount of (rER) that organized into aggregates of parallel cisternae, ribosomes (r), well developed Golgi apparatus $(\mathrm{G})$, mitochondria $(\mathrm{m})$ with intact membranes and regular cristae. TEM, X4800, X10,000, respectively; (1C, 1D) GA3-treated group showing Purkinje cells with a nucleus $(\mathrm{N})$ and a nucleolus (n). Marked in folding of the nuclear envelope (arrow heads) is detected. Destructed and interrupted cell membrane (curved arrows) is observed. Notice the presence of marked empty spaces (*) between the cells. The cytoplasm is rarified and reveals vacuoles (v), lysosomes (L), distorted or swollen mitochondria with rarified or electron dense matrix and ill-defined cristae $(\mathrm{m})$, few short or dilated strands of (rER) and apparent decrease in the amount of free ribosomes (r). TEM, X4800, X10,000, respectively; (1E) GA3/silymarin-treated group showing nearly normal ultrastructure; euchromatic nucleus (N) with prominent nucleolus (n) and well-defined nuclear envelope. A slightly electron-dense cytoplasm is observed. The cytoplasm is rich with abundant amount of (rER) organized into aggregates of parallel cisternae, ribosomes $(\mathrm{r})$ and mitochondria $(\mathrm{m})$ with intact membranes and regular cristae. 


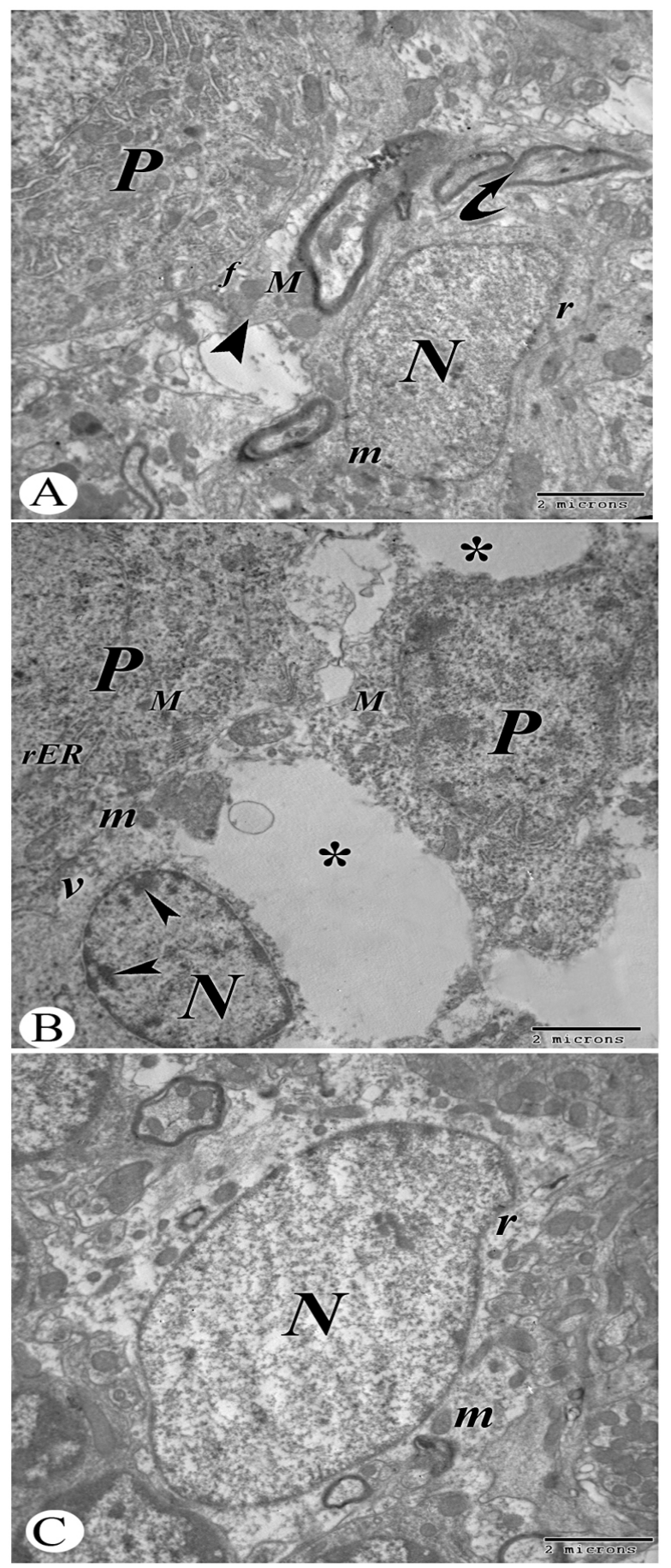

Fig. 10: TEM of the Bergmann astrocytes of adult rats' cerebellar cortex. (1A) Control group showing the astrocytic process (arrow head) ensheathing a Purkinje cell $(\mathrm{P})$. The cell has pale euchromatic nucleus $(\mathrm{N})$. Ribosomes $(\mathrm{r})$ and few mitochondria $(\mathrm{m})$ are present in the pale cytoplasm. The astrocytic process contains few gliofilaments (f) and mitochondria (M). Notice the presence of myelinated nerve fibers (curved arrow); (1B) GA3-treated group showing a Bergmann astrocyte surrounding Purkinje cells (P). The astrocyte has euchromatic nucleus $(\mathrm{N})$ with peripheral chromatin condensation (arrow heads). It appears shrunken with mere shell of cytoplasm. Vacuoles (v) and electron dense distorted mitochondria $(\mathrm{m})$ are observed in the cytoplasm. Note the presence of distorted mitochondria $(\mathrm{M})$ and few strands of (rER) in the cytoplasm of Purkinje cells. Marked empty intercellular spaces are seen (*); (1C) GA3/silymarin-treated group showing a Bergmann astrocyte with an oval nucleus $(\mathrm{N})$. Ribosomes $(\mathrm{r})$ and few mitochondria $(\mathrm{m})$ are present in the cytoplasm.

TEM, X7200. 


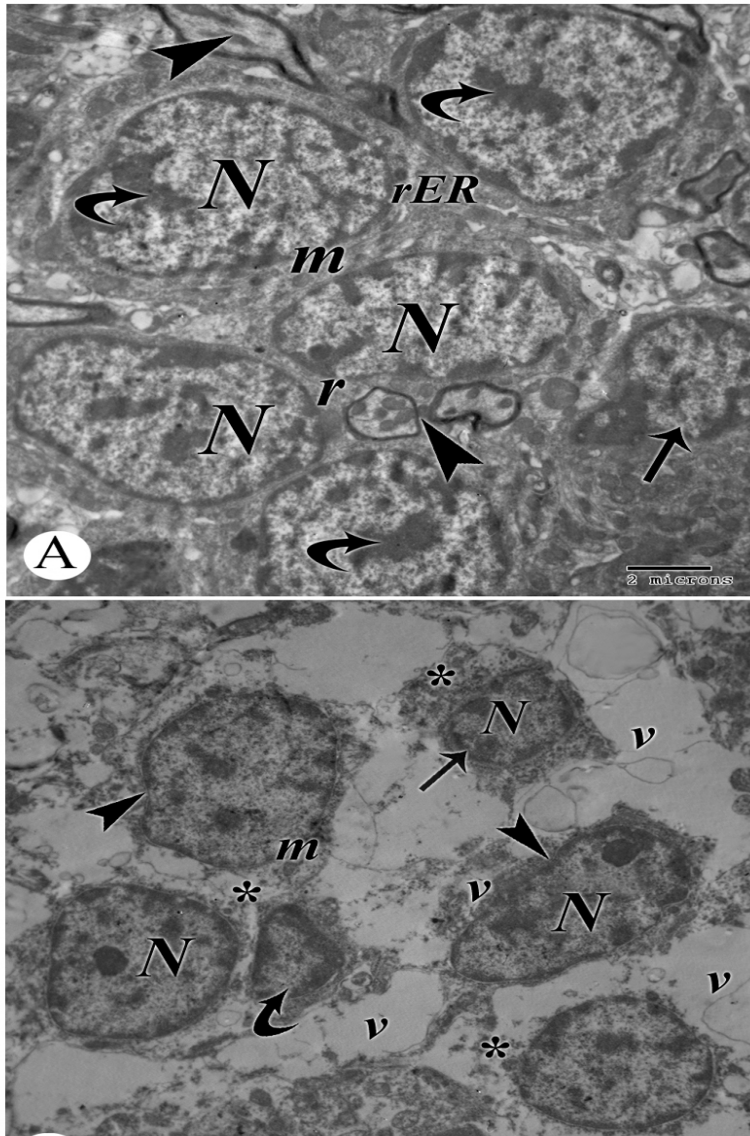

B

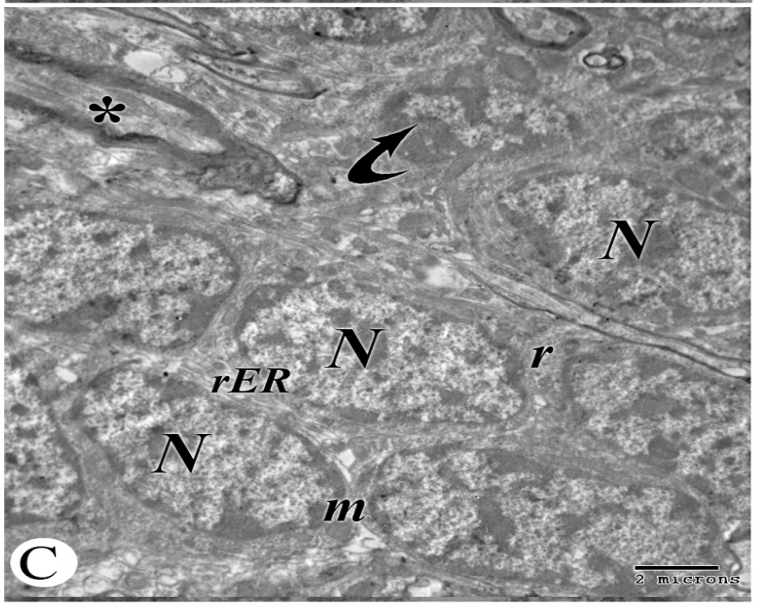

Fig. 11: TEM of the granule cells of adult rats' cerebellar cortex. (1A) Control group showing rounded or oval nuclei (N) with clumps of heterochromatin (curved arrows). The cytoplasm contains ribosomes (r), few strands of (rER) and few mitochondria (m). There are myelinated nerve fibers (arrowheads) in between the granule cells. Note the presence of oligodendrocytes (arrow) with condensed chromatin among the granule cells; (1B) GA3-treated group showing the granule cells with rounded or oval nuclei (N). Some cells show irregular nuclear envelope (arrow heads). Other cells show peripheral chromatin condensation of their nuclei (arrow). Rarified cytoplasm $(*$ ) contains distorted mitochondria (m). Marked intracellular and intercellular vacuolations (v) are present. Oligodendrocytes (curved arrow) with condensed nuclear chromatin can be noticed; (1C) GA3/silymarin-treated group showing more or less normal granule cells containing rounded or oval nuclei $(\mathrm{N})$ with heterochromatin. The cytoplasm reveals ribosomes $(\mathrm{r})$, few strands of (rER) and few mitochondria $(\mathrm{m})$. Myelinated nerve fibers $(*)$ and oligodendrocytes (curved-arrow) are observed between the cells.

TEM, X4800. 


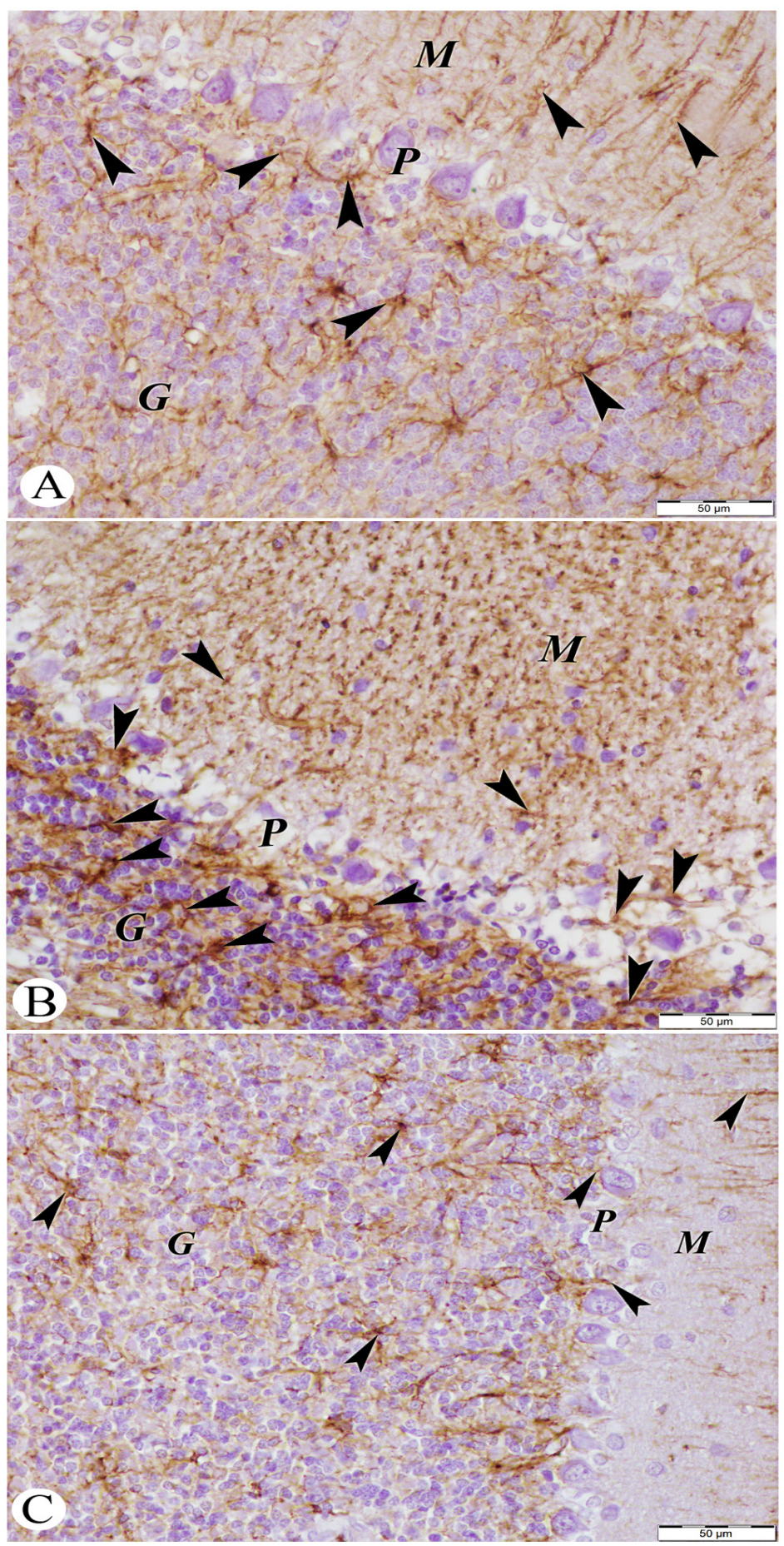

Fig. 12: Glial fibrillary acidic protein (GFAP) immunohistochemically stained sections in the adult rats' cerebellar cortex. (1A) Control group showing the cortical layers (M), (P) and (G) which reveal apparently large GFAP positive cells (arrow heads) with relatively longer processes as compared with the previous age; (1B) GA3-treated group showing more numerous and larger GFAP positive cells with thicker processes (arrow heads) in comparison with those of the adult control group in the three cortical layers; (1C) GA3/silymarin-treated group showing Positive expression of GFAP (arrow heads) in the three cortical layers which is nearly similar to that in the control group. The expression of GFAP reveals noticeable reduction compared to that in GA3 treated rats.

GFAP immunostain, X400. 


\section{DISCUSSION}

GA3, which is one of the plant growth regulators (PGRs), is widely used to increase the growth of many fruits and vegetables, besides its roles against harmful agricultural pests. Although GA3 is widely used in agriculture, a little is known about its effects as regards the mammalian tissues. Therefore, this study was carried out to investigate the histological changes in the cerebellar cortex of albino rats after GA3 treatment and to detect any possible protective role of silymarin when given concomitantly with GA3.

Cerebellum is a region of the brain that plays an important role in the motor control. It is also involved in some complex cognitive processes; emotions, behavior, learning and memory. It receives inputs from the sensory system of the spinal cord and from different parts of the brain and integrates this information to fine-tune motor activity $^{[21]}$. The cerebellum was particularly vulnerable to developmental and environmental insults because of its long developmental schedule ${ }^{[22]}$.

In this study, light microscopic examination showed that the cerebellar cortex of two weeks old control animals was formed of four cortical layers; the external granular layer had rounded cells. The molecular layer had rounded and oblongata cells. The Purkinje cells contained rounded vesicular nuclei and prominent nucleoli. The inner granular layer was formed of well -defined clumps of rounded cells. In harmony with the present results, a study demonstrated that, the molecular layer was hardly recognizable at the 2nd day postnatal. He added that, within one week, this layer enlarged ${ }^{[23]}$. In accordance, some investigators found that the maturity of the Purkinje cells was detected two weeks post-natally ${ }^{[24]}$. Other investigators added that the development of the granular layer occurred mainly postnatally as the differentiation of the granular layer was closely related to the development of the Purkinje layer. They postulated that the Purkinje cells were crucial for the control of the granular cells differentiation ${ }^{[25]}$.

The cerebellar cortex of the control adult animals (lactating mothers) in the present work had the following layers; the molecular layer, the Purkinje layer was formed of a single row of pyriform cells and the granular layer was formed of well-defined clumps of rounded cells. Non cellular areas called cerebellar islands (glomeruli) were also seen in between the granular cells. In line with these findings, some investigators showed that the outer molecular layer was formed of a complex network of glial and neuronal processes ${ }^{[26]}$. Concomitant with the present results, other studies reported that the inner granular layer, in rat appeared as a few scattered cells at birth which were gradually demarcated at 7 th- 25 th postnatal day and then increase in the cellularity by 21 stpostnatal day ${ }^{[27]}$.

Ultrastructurally, the Purkinje cells of the control groups in the present work were identified by their position, euchromatic nuclei and well defined nucleoli. The nuclear envelope was characterized by slight indentation (two weeks old) and shallow dimples in which strands of rough endoplasmic reticulum accumulated (adult age). In accordance with the present results, some researchers revealed that Purkinje cells were clearly distinguished by their large size, euchromatic nuclei, shallow dimples of the nuclear envelope and the presence of mitochondria with regular cristae and cisternae of rough endoplasmic reticulum as well in the cytoplasm ${ }^{[28]}$.

In the current study, electron microscopic examination of the granular cells of the control groups exhibited rounded nuclei. They had little cytoplasm. These findings were confirmed by other investigators ${ }^{[29]}$. They reported that in rat, the granular neurons had rounded nuclei with condensed heterochromatin at the periphery of the nuclei and relative amount of cytoplasm. In harmony with the present findings, other researchers reported two stages during differentiation of the granular cells; the first stage occurred in rats during the first two weeks of postnatal development and was characterized by the expansion of mossy fiber rosettes, which contained synaptic vesicles. The second stage included the formation and stabilization of glomeruli (from day 15 to day 45). Meanwhile, there were increases in the number of synaptic vesicles in mossy fiber terminals and in contacts with the dendrites of granular cells, which form blebs (spines) that contained endoplasmic reticulum cisterns and mitochondria ${ }^{[30]}$.

Astrocytes were considered as poly-functional cells that were distributed in the central nervous systems of all vertebrates. They exhibited diverse anatomical characteristics and functional properties. They played key role in the homeostasis of the excitatory neurotransmitter glutamate $^{[31]}$. Moreover, astrocytes participated in all important central nervous system functions; energy metabolism, blood flow regulation, $\mathrm{K}$ and $\mathrm{H}$ buffering, immune defense mechanism and neurotransmission ${ }^{[32]}$. Glial Fibrillary Acidic Protein (GFAP) is considered as an intermediate filament protein found almost exclusively in astrocyte ${ }^{[33]}$. The current study revealed an apparent increase in the expression of GFAP positive cells gradually from two weeks to adult age in the immunostained sections. Similarly, some investigators stated that GFAP is well known as a specific marker of mature astrocytes of the nervous system and its expression is necessary for the normal white matter architecture and blood brain barrier integrity ${ }^{[34]}$.

After GA3 administration, features of neuronal insult were obvious especially in the Purkinje and the granular layers. In accordance with that, other investigators considered the Purkinje and the granular cells as the most important target for the toxic substance in the cerebellum. Light microscopic examination of the cerebellar cortex of two weeks GA3-treated rats showed disturbance in the 
linear organization of the Purkinje cells. They exhibited rarified nuclei and darkly stained cytoplasm ${ }^{[35]}$. In accordance with the current results, it was found that oral exposure of rats to GA3 during late pregnancy and early postnatal periods resulted in obvious histopathological changes of the suckling rats and their mothers ${ }^{[36]}$. Some authors reported that oral administration of GA3 to the pregnant Wistar rats in late pregnancy and early postnatal periods resulted in marked neurotoxicity in the cerebellum of GA3-treated suckling rats which was detected as an abnormal development of the external granular layer and a loss of Purkinje cells. They recorded inhibition of acetylcholinesterase (AChE) activity in the cerebellum of the suckling rats, suggests that GA3 was incorporated in the nervous system of the suckling pups by milk transfer. They also noticed that these abnormal histological manifestations were correlated with abnormal biochemical parameters as they detected increase in malondialdehyde level and a decrease in the activity of the antioxidant enzyme of catalase, glutathione peroxidase and superoxide dismutase in the cerebellum of suckling rats ${ }^{[14]}$. In the present study, marked spongiosis was seen in the three cortical layers as vacuolated areas. In accordance with that, some investigators stated that the structural changes associated with PGRs, such as increased vacuolization and membrane blebbing, were correlated with oxidative stress and depletion of the glutathione ${ }^{[37]}$.

GA3-treated adult rats in this work showed that some Purkinje cells were displaced downwards in the granular layer and upwards in the molecular layer. The Purkinje cells appeared shrunken and irregular. Most of the granule cells showed shrunken cell bodies and hardly identified nuclei. In a similar study, it was found that the rats treated with GA3 had prominent neurotoxic manifestation; the Purkinje cells showed disturbed linear organization with marked disarrangement. Also, the granular cells had patchy cell loss in some areas or depletion in other areas. They added that in between the affected cells, the cerebellar islands showed increased eosinophilia ${ }^{[8]}$. Our data was confirmed by other investigators who observed decrease in the activity of the acetylcholinesterase (AChE) in the brain of adult rats that were treated with indole -3- butyric acid which is one of the PGRs ${ }^{[38]}$.

Electron microscopic examination of cerebellar cortex of GA3-treated rats at two weeks old and adult age in this study showed obvious features of neurodegeneration. Atrophic changes were evident in some Purkinje neurons leaving empty spaces. Dilated cisternae of rough endoplasmic reticulum, apparent decrease in the amount of free ribosomes and lysosomes were noticed. Some mitochondria were damaged or swollen and others were vacuolated. In harmony with these results, other investigators recorded numerous ultrastructural manifestations in the GA3-treated rats such as cytoplasmic vacuolation, dilated rough endoplasmic reticulum and markedly affected mitochondria of the Purkinje cells. They noticed the presence of small vesicles of the rough endoplasmic reticulum in the form of clusters near the Golgi bodies and they considered that as an indicator of the disturbance in the vesicular transport mechanism between the rough endoplasmic reticulum and the Golgi apparatus ${ }^{[8]}$. In the current research, the observed ultrastructural effects were explained by some investigators as a structuralfunctional response that could enable the cells release the oxidative stress secondary to GA3 toxicity ${ }^{[39]}$.

Ultrastructurally, the granular cells of GA3- treated rats in the present work had rounded or oval nuclei with marked chromatin condensation. Some cells showed rarified cytoplasm that contained distorted mitochondria with a heterogeneous matrix. The degenerative changes in the granular cells were considered by some authors to be secondary to those of the Purkinje cells. They reported that the affected Purkinje cells failed to make normal contact with the granular cells; this would result in the loss of normal synchronism between both types of cells that in turn minimized their regulatory role on them ${ }^{[40]}$. In the present results, the observed nuclear chromatin condensation could be explained by the report of the other investigators who stated that dying neurons could undergo condensation and dissolution of chromatin ${ }^{[41]}$.

In the current study, the vacuolation observed in the Purkinje and granular cells were explained by some researchers as a result of marked disturbances in lipid inclusions $^{[42]}$. Some investigators suggested that the vacuolation might be due to the cells injury which resulted in the increased production of reactive oxygen species (ROS) which probably attacked the membranes and altered their permeability ${ }^{[4]}$. Other investigators added that the lipid peroxidation was considered as an autocatalytic mechanism leading to the oxidative destruction of cellular membranes. In turn their destruction could lead to cell death and also to the production of toxic free radicals. The most important one of these free radicals was malondialdehyde $(\mathrm{MDA})^{[44]}$.

The observed histological and ultrastructural effects were confirmed by the applied immunohistochemical staining. Features of activation of Bergmann astrocytes were evident in the present study as increased expression of GFAP due to neuronal damage caused by GA3 administration. It was found that the astrocytes reacted rapidly to any nervous system insult by the production of numerous neurotoxic substances and more GFAP. These effects were considered as a marker protein for astrogliosis ${ }^{[34]}$. In the present study, the observed features of reactive astrocytes might be due to compensatory mechanism following neurodegeneration. Similar process was reported following neurotoxicity ${ }^{[45]}$. The astrocytes had been involved in the processes of neuronal homeostasis and synaptic plasticity and glial cell activation might result as a secondary mechanism of cell 
death or neuroprotective response ${ }^{[46]}$.

A significant increase in the thickness of the Purkinje layer of GA3-treated group as compared to control group was observed in both age groups; two weeks and adult. Moreover, the two weeks old rat showed a significant reduction in the thickness of the external granular layer of group II as compared to group I. These results were in parallel with the histological and immunohistochemical results.

Several studies reported that the nervous system is considered as the principal target organ for the PGRs ${ }^{[38]}$. The nervous system is particularly vulnerable to oxidative damage because of its low levels of the defensive mechanisms against oxidant toxicity, in addition to high oxygen consumption rate and high levels of polyunsaturated fatty acids ${ }^{[47]}$. It was reported that the damaging effects of PGRs was associated with the production of ROS. The brain is sensitive to attacks by ROS due to high oxygen uptake and many autooxidizable neurotransmitters ${ }^{[48]}$. Therefore, in the condition in which the generation of free radicals exceeds the ability of antioxidant defense mechanisms, oxidative stress might result in pathophysiological aberrations; cellular dysfunction, membrane degradation and apoptosis ${ }^{[49]}$. ROS could damage major cellular component such as DNA, membranes, lipids and carbohydrate $^{[50]}$. Moreover, oxidative stress was one of the molecular mechanisms that enhanced toxicity. It occurred as a result of the disturbance influence of xenobiotics on the antioxidant enzymes. Liberation of oxygen free radicals and ROS was produced in tissues via the effects of oxidative stress $^{[51]}$. The imbalance between the production of free radicals and antioxidant defense system result in tissue damage $\mathrm{e}^{[52]}$.

In this study, co-administration of silymarin alleviated the neurotoxic effects of GA3 on the cerebellum. A histological pattern nearly similar to the control group was noticed in the GA3/silymarin-treated groups (two weeks old and the adult groups). Light microscopic examination of the cerebellar cortex of two weeks old rats showed more or less normal appearance of the molecular, granular and Purkinje cell layers. The Purkinje cells retained their normal linear organization. The cerebellar cortex of the adult rats exhibited its well- known architecture. The Purkinje cells arranged in a single row and retained their characteristic pyriform shape. Several studies had shown the neuroprotective effects of silymarin by using in vitro and in vivo models. Some investigators found that silymarin administration $(200 \mathrm{mg} / \mathrm{kg})$ for 2 weeks could decrease 6-hydroxydopamine-induced Parkinson's in a rat model. The neuroprotective effects of silymarin in this model were believed to be through the inhibition of oxidative stress ${ }^{[53]}$. In another study, silymarin (200 and $400 \mathrm{mg} / \mathrm{kg}$ doses) was found to inhibit oxidative stress in aged and young rat brains ${ }^{[54]}$. Silymarin significantly decreased protein oxidation in the hippocampus and cortex tissues of animals ${ }^{[55]}$. It was also considered as a potent antiinflammatory agent modulating the different cells involved in this process ${ }^{[56]}$. In accordance, other investigators claimed a short-term silymarin treatment resulted in increased the levels of dopamine and norepinephrine levels in the cerebellum which indicated that silymarin had no adverse effect on the brain amine metabolism and might have marginal serotonergic, dopaminergic, and noradrenergic effects $^{[57]}$. Interestingly, evidence from in vitro studies by using related flavonoid compounds indirectly supported the hypothesis of the interaction between silymarin and various neurotransmitters ${ }^{[56]}$.

Compared to the control rats, the cerebellar cortex of silymarin treated rats in this work exhibited a nearly similar ultrastructural appearance. Apparently healthy mitochondria and short strands of rough endoplasmic reticulum were present in the Purkinje cells (two weeks old rats). The Purkinje cells of adult rats had slightly electrondense cytoplasm that was rich with rough endoplasmic reticulum and mitochondria with intact membranes. The ultrastructural examination of the granule cells of both age groups showed the presence of rounded or oval nuclei. Positive expression of GFAP was noticed in this group which was nearly similar to that in the control groups. Alike, silymarin had reported to have the ability to protect microglia and astroglia from oxidative insults ${ }^{[58]}$. Others added that the silymarin-mediated inhibition of gliosis was attributed to the inhibition of nuclear factor kappa-light-chain-enhancer of activated B cells (NF- $\mathrm{B}$ ) activation $^{[59]}$. Furthermore, silymarin directly inhibited the activity of monoamine oxidase in the C6 astrocyte cell line ${ }^{[60]}$. Compared to control rats, the morphometric results showed no significant changes in the silymarin-treated rats in both age groups.

Some investigators stated that silymarin had different mechanisms as an antioxidant; through its direct free radical scavenging, by preventing the formation of free radical, by inhibiting specific enzymes, or by preserving the integrity of electron-transport chain of the mitochondria ${ }^{[61]}$. In context, others reported that one of the mechanisms responsible the capacity of silymarin to decrease oxidative stress was the protective effect of silymarin on mitochondrial structure and function. Indeed, silymarin protected the mitochondria from pathological changes by triggering pro-survival cell signaling ${ }^{[62]}$. It has been suggested that silymarin might be the ideal neuroprotective agent against many conditions in which cellular damage was a consequence of oxidative stress through the inhibition of neurological deficits and apoptosis responses ${ }^{[63]}$.

\section{CONCLUSION}

Exposure of rats to GA3, during late pregnancy and lactating periods affects the structure of the rat's cerebellar cortex of lactating mothers and the structure and maturation of that of their pups. In addition, silymarin could protect 
the cerebellum against GA3-induced oxidative stress probably through its antioxidant activity. Therefore, its supplementation could be a new approach for the reduction in nervous system complication due to GA3 exposure. Also, occupational and environmental exposure to GA3 should be limited.

\section{CONFLICT OF INTEREST}

There are no conflicts of interest.

\section{REFERENCES}

1. Fishel FM. Gibberellins. Agronomy department, Florida cooperative extension service, Institute of food and agricultural sciences, University of Florida, USA 2006.

2. Osborne DJ, McManus MT. Hormones, signals and target cells in plant development. 1st ed. 1 . 266, Cambridge University Press 2005.

3. Troudi A, Samet AM, Zeghal N. Hepatotoxicity induced by gibberellic acid in adult rats and their progeny. Experimental and Toxicologic Pathology Journal 2010; 62(6): 637-642.

4. Neil AC, Reece JB. Phytohormones (plant hormones) and other growth regulators: Gibberellins. In: Biology. 6 ed., (San Fransisco, Benjamin Cummings) 2002; 145.

5. Sakr SA, Okdah, YA, EL-Abd SF. Gibberellin A3 induced histological and histochemical alterations in the liver of albino rats. Science Asia 2003; 29: 327-331.

6. Tomlin CDS. Gibberellic acid. In: The e-Pesticide Manual. 13 ed., edited by Tomlin, C.D.S. (Hampshire, UK, British Crop. Protection Council) 2004; Chapter 3, 5.

7. Celik I, Tuluce Y, Isik I. Evaluation of toxicity of abscisic acid and gibberellic acid in rats: 50 days drinking water study. Journal of Enzyme Inhibition and Medical Chemistry 2007; 2: 219-226.

8. Abou-zeid NRA, Abd-Ellah H F. Neurotoxic Effects of Gibberellic Acid (GA3) and its Withdrawal in Adult Male Albino Rats: A Light and Electron Microscopic Study.Global Journal of Pharmacology 2015; 9 (3): 222-233.

9. Cho S, Lee Y, Lee S, Choi YJ , Chung HW. Enhanced cytotoxic and genotoxic effects of gadolinium following ELF-EMF irradiation in human lymphocytes. Drug and Chemical Toxicology 2014; 37(4) : 440- 447.
10. Pradhan SC, Girish C. Hepatoprotective herbal drug, silymarin from experimental pharmacology to clinical medicine. Indian Journal of Medical Research 2006; 124(5): 491-504.

11. Chen YH, Lin FY, Liu PL, HuangYT, Chiu JH. Chang YC, Man KM, Hong CY, Ho YY, Lai MT. Antioxidative and hepatoprotective effects of magnolol on acetaminophen-induced liver damage in rats .Archives of Pharmacal Research Journal 2009; 32 ( 2): 221-228.

12. Paull JA, Fairbrother A. Pregnancy diagnosis by vaginal lavage in deer mice, Peromyscusmaniculatus. Journal of Experimental Zoology 1985; 233: 143-149.

13. Council of European Communities. Council instructions about the protection of living animals used in scientific investigations. European journal of Communication (JO86 / 609/CEE) 1986; 1-18

14. Troudi A, BouazizH, Soudani N, Ben AmaraI, Boudawara $\mathrm{T}$, Touzani H, Lyoussi B , Zeghal N. Neurotoxicity and oxidative stress induced by gibberellic acid in rats during late pregnancy andearly postnatal periods: Biochemical and histological changes. Experimental and Toxicologic Pathology Journal 2012; 6: 583-590.

15. Mansour HH, Hafez HF, Fahmy NM. Silymarin modulates cisplatin-induced oxidative stress and hepatotoxicity in rats. Journal of Biochemistry and Molecular Biology 2006; 39: 656-661.

16. Gage GJ, Kipke DR, Shain W. Whole animal perfusion fixation for rodents. Journal of Visualized Experiments 2012; 65: 3564.

17. Bancroft JD, Gamble M. Theory and practice of histological techniques. Spencer LT, Bancroft JD. 6th ed. London: Churchill Livingstone2007; 179.

18. Hayat MA. Principles and techniques of electron microscopy: biological applications. 4th ed. Edinburgh, UK: Cambridge University Press 2000; 37-59.

19. Cattoretti G, Pileri S, Parravicini C, Becker MH, Poggi S, Bifulco C, Key G, D’Amato L, Sabattini E, FeudaleE, Reynolds F, GerdesJ, Rilke F. Antigen unmasking on formalin-fixed, paraffin- embedded tissue sections .The Journal of Pathology 1993 ;171(2): 83-98.

20. Dean AG, Dean JA, Coulombier D. et al. Epi-Info (6.1): A word processing data base and statistical program for epidemiology and micro-computer 
office, Center for disease control, Atlanta Georgia, USA 2000; 8

21. Wolf U, Rapoport MJ, Schweizer TA. Evaluating the affective component of the cerebellar cognitive affective syndrome. The Journal of Neuropsychiatry and Clinical Neuroscience2009; 21 (3): 245-253.

22. Ulupinar E, Yucel F , Ortug G. The effects of prenatal stress on the Purkinje cell neurogenesis. Neurotoxicology and teratology 2006; 28(1): 86-94.

23. Heinsen H. Quantitative Anatomical Studies on the Postnatal Development of the Cerebellum of the Albino Rat. Anatomy and Embryology journal 1977; 151:201-218.

24. Brown MC, Hopkins WH, Keynes RJ. Essentials of neural development, Cambridge University, Academic Press1991

25. Smeyne RJ, Chu T, Lewin A, Bian F, Crisman SS, Kunsch C, Lira SA, Oberdick J. Local control of granule cell generation by cerebellar Purkinje cell .Molecular and Cellular Neuroscience 1995; 6(3): 230-251.

26. Matta WM, Kamal MM, Abdel-Kader G A. Qualitative and quantitative study on the effect of neonatal undernutrition on the postnatal development of the vermian cerebellum of mouse. Egyptian Journal of Anatomy 1979; 2: 59-76.

27. Gaber MA, Mohamed RS, HassaneinK. Effect of inorganic lead on the postnatal development of the cerebellum. Assuit Veterinary Medical Journal $1985 ; 25: 27-38$

28. El-Shafeia MDM, Kamel AMF, Mostafa MEA. Effect of aluminum on the histological structure of rats' cerebellar cortex and possible protection by melatonin. The Egyptian Journal of Histology 2011; 34 :239-250.

29. Esrefoglu M, Gepdiremen A, Kurus M. Ultrastructural clues for glutamate induced necrosis in parietal and cerebellar neurons .Fundamental and Clinical Pharmacology 2003; 17 (3): 342-347.

30. Zimatkin SM, Karnyushko OA. Synaptogenesis in the Developing Rat Cerebellum. Neuroscience and Behavioral Physiology 2017; 47: (6), 631-636

31. Lee A, Pow DV. Astrocytes: Glutamate transport and alternate splicing of transporters. The International Journal of Biochemistry and Cell Biology 2010; 42 (12): 1901-1906.

32. Oberheim NA, Goldman SA, Nedergaard M. Heterogeneity of astrocytic form and function Methods in Molecular Biology 2012; 814: 23-45.

33. Der Perng M, Su M, Wen SF, Li R, Gibbon T, Prescott AR, Brenner M, Quinlan RA. The Alexander disease-causing glial fibrillary acidic protein mutant, $\mathrm{R} 416 \mathrm{~W}$, accumulates into Rosenthal fibers by a pathway that involves filament aggregation and the association of alpha B-crystallin and HSP27. The American Journal of Human Genetics 2006; 79(2): 197-213.

34. Eng LF, Ghirnikar RS. GFAP andastrogliosis. Brain Pathology 1994; 4(3): 229-237.

35. Fonumm F, Lock EA. Cerebellum as a target for toxic substance. Toxicology Letters 2000; 15 (112-113): 9-16.

36. Troudi A, Ben AmaraI, SoudaniN, Samet AM, Zeghal N. Oxidative stress induced by gibberellic acid on kidney tissue of female rats and their progeny: biochemical and histopathological studies. Journal of Physiology and Biochemistry 2011; 67: 307-316.

37. Celik I, Tuluce Y. Determination of toxicity of subacute treatment of some plant growth regulators on rats. Environmental Toxicology 2007; 22(6) : 613-619.

38. Yilmaz Z, Celik I. Neurotoxic andimmunotoxic effects of indole-3-butyric acid on ratsat subacute and subchronic exposure. Neurotoxicology 2009; $30: 382-385$.

39. Hussein WF, Farahat FY, Abass MA, Shehata AS Hepatotoxic Potential of Gibberellic Acid (GA3) in Adult Male Albino Rats. Life Science Journal 2011; 8(3):373-383.

40. Saad El-Dien HMS, EL Gamal DA, Mubarak HA, Saleh SM. Effect of fluoride on rat cerebellar cortex: Light and Electron microscopic studies. Egyptian Journal of Histology 2010; 33: 245 - 256.

41. Olivi A, Gilbert M, Duncan KL, Corden B, Lenartz D, Brem H. Direct delivery ofplatinumbased antineoplastics to the centralnervous system: A toxicity and ultrastructural study. Cancer Chemotherapy and Pharmacology Journal 1993; 31: 449-454. 
42. Sherlock S, Dooley J. Diseases of the Liver and Biliary System. 9 ed., (Oxford, Boston:Blackwell Scientific Publications) 2002; 114

43. Robbins SL, Angell M. Basic Pathology 2 ed., (W. B. Saunders Company, Philadelphia) 1976.

44. Çelik İ, Özbek H, Tuluce Y. Effects of subchronic treatment of some plant growth regulators on serum enzyme levels in rats. Turkish Journal of Biology 2002; 26: 73-76.

45. Borlongan CV, Yamamoto M, Takei N, Kumazaki M, Ungsuparkorn C, Hida H, Sanberg PR, Nishino $\mathrm{H}$. Glial cell survival is enhanced during melatonin induced neuroprotection against cerebral ischemia. FASEB Journal 2000; 14(10): 1307-1317.

46. Vernadakis A. Glia-neuron intercommunications and synaptic plasticity. Neurobiology Journal 1996; 49(3): 185-214.

47. Samson FE, Nelson SR. The aging brain,metals and oxygen free radicals. Cellular and Molecular Biology Journal 2000; 46 : 699-707.

48. Clarke DD, Sokoloff L. Circulation and energy metabolism of the brain. In: Siegel, G.J., Agranoff, B.W., Albers, R.W., Fisher, S.K., Uhler, M.D. editors. Basic neurochemistry: molecular, cellular and medical aspects. 6th ed. Philadelphia: Lippincott Philadelphia: Raven 1999; 637-669.

49. Halliwell B. Oxidative stress and neurodegeneration: where are we now? Neurochemistry Journal 2006; 97: 1634-1658.

50. Bhalla P, Dhawan DK. Protective role oflithium in ameliorating the aluminium-induced oxidative stress and histological changes in rat brain. Cellular and Molecular Neurobiology 2009; 29: 513-521.

51. Celik I, Tuluce Y, Isik I. Influence of subacute treatment of some plant growth regulators on serum marker enzymes and erythrocyte and tissue antioxidant defense and lipid peroxidation in rats. Journal of Biochemical and Molecular Toxicology 2006; 20(4): 174-182.

52. Oruc EO, Uner N. Marker enzyme assessment in the liver of cyprinuscarpio (L.) exposed to 2, 4-D and azinphosmethyl. Journal of Biochemical and Molecular Toxicology 2002; 16(4): 182-188.

53. Baluchnejadmojarad T, Roghani M, Mafakheri M. Neuroprotective effect of silymarin in 6-hydroxydopamine hemi-parkinsonian rat: involvement of estrogen receptors and oxidative stress. Neuroscience Letters 2010; 480(3): 206-210.

54. Galhardi F, Mesquita K, Monserrat JM, Barros DM. Effect of silymarin on biochemical parameters of oxidative stress in aged and young rat brain. Food and Chemical Toxicology journal 2009; 47(10): 2655-2660.

55. Mehri S, Dadesh Q, Tabeshpour J, Hassani FV, Karimi G, Hosseinzadeh H. Evaluation of the neuroprotective effect of Silymarin on Acrylamide-Induced Neurotoxicity. Jundishapur Journal of Natural Pharmaceutical Products 2016; 11(4): 1-6.

56. Middleton E, Kandaswami C, Theoharides TC. The effects of plant flavonoids on mammalian cells: implications for inflammation, heart disease and cancer. Pharmacological Review Journal 2000; 52: 673-751.

57. Osuchowski MF, Johnson VJ, He Q, Sharma RP. Alterations in Regional Brain Neurotransmitters by Silymarin, a Natural Antioxidant Flavonoid Mixture, in BALB/c Mice Pharmaceutical Biology 2004; 42(4-5): 384-389.

58. Tsai MJ, Liao JF,Lin DY, Huang MC, Liou DY, Yang HC, Lee HJ, Chen YT, Chi CW, Huang WC, Cheng H. Silymarin protects spinal cord and cortical cells against oxidative stress and lipopolysaccharide stimulation. Neurochemistry International 2010; 57: 867-875.

59. Wang MJ, Lin WW, Chen HL, Chang YH, Ou HC, Kuo JS, Hong JS, Jeng KCG. Silymarin protects dopaminergic neurons against lipopolysaccharideinduced neurotoxicity by inhibiting microglia activation. The European Journal of Neuroscience 2002; 16: 2103-2112.

60. Mazzio EA, Harris N, Soliman KFA. Food constituents attenuate monoamine oxidase activity and peroxide levels in C6 astrocyte cells. Planta Medica Journal 1998; 64: 603-606.

61. Surai PF. Silymarin as a natural antioxidant: An overview of the current evidence and perspectivesantioxidants. Antioxidants 2015; 4(1): 204-247.

62. Rolo AP, Oliveira PJ, Moreno AJM, Palmeira CM. Protection against post-ischemic mitochondrial injury in rat liver by silymarin or TUDC. 
Hepatology Research Journal 2003; 26: 217-224.

63. Raza SS, Khan MM, Ashafaq M, Ahmad A, Khuwaja G , Khan A, Siddiqui MS, Safhi MM, Islam F. Silymarin protects neurons from oxidative stress associated damages in focal cerebral ischemia: a behavioral, biochemical and immunohistological study in Wistar rats. Journal of the Neurological Sciences 2011; 309 (1-2): 45-54. 


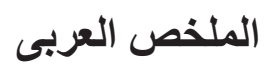

دراسة هستولوجية و هستوكيميائية مناعية للاور الوقائي المحتمل لمادة سيليمارين على تسمم قثرة

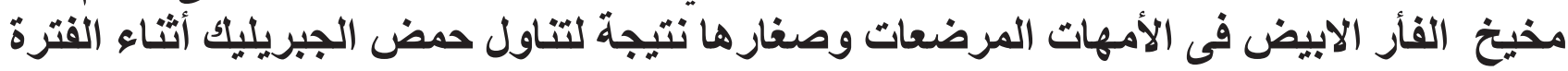

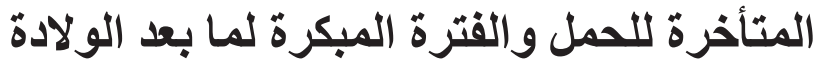

\author{
هبة كمال محمد و هاله زين العابدين محمد

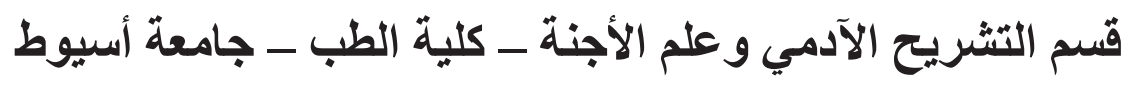

المقدمة : تستخدم منظمات نمو النبات وخاصه حمض الجبريليك لزيادة الانتاج واتاحة النباتات طول العام. ونم اعتبار مادة

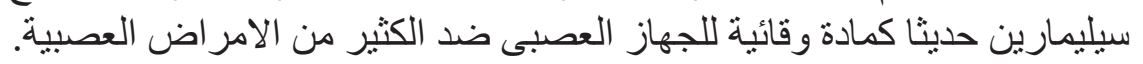

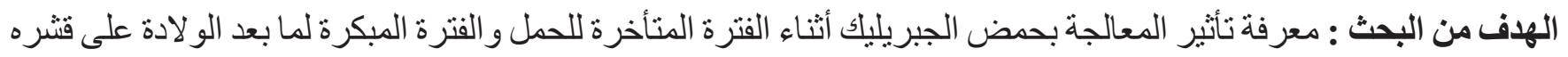

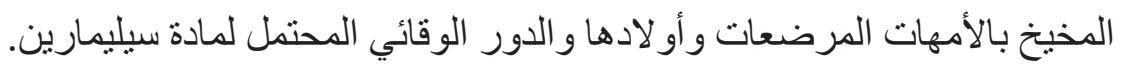

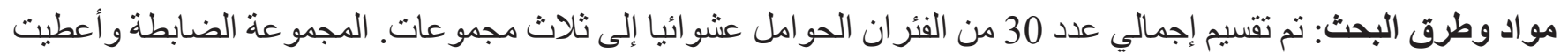

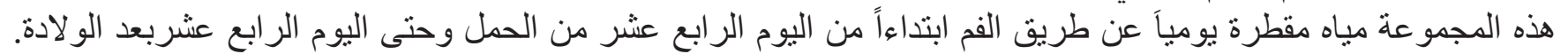

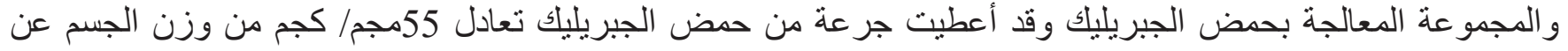

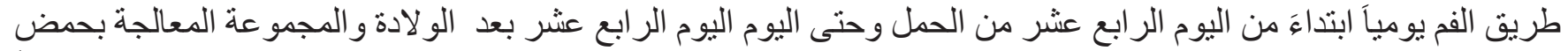

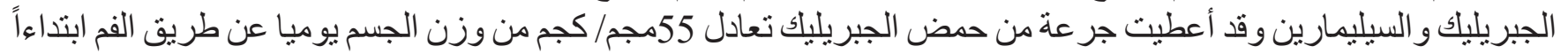

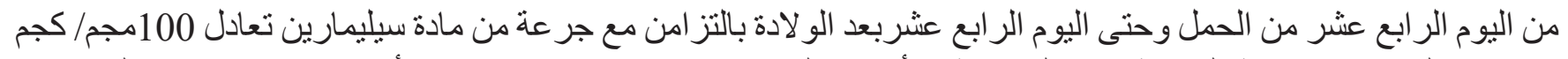

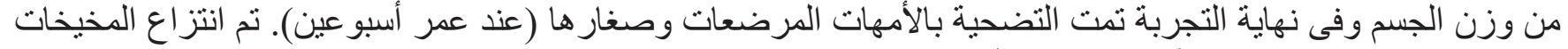

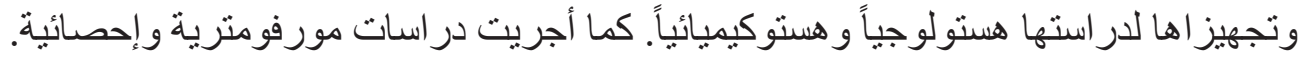

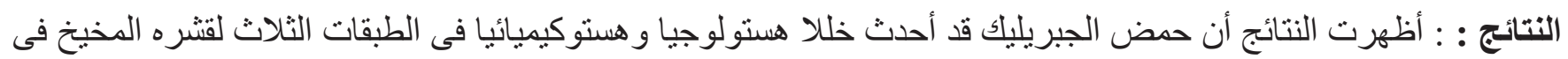

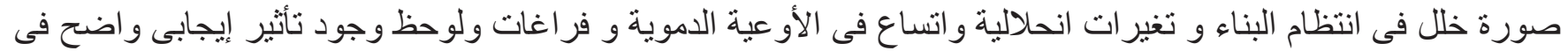

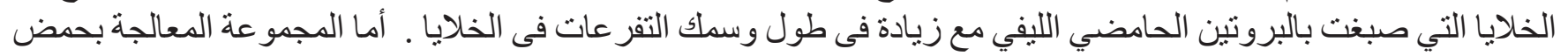

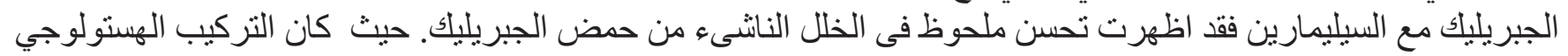

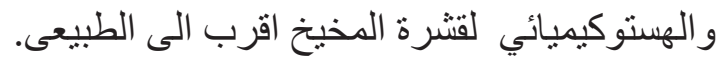
الإستتتاج : أن تتاول مادة السيليمارين له تأثثر وقائى من التسمم العصبى النانشىء فى قثرة المخيخ نتيجة التعرض لحمض الجبريليك. 